From the Department of Plastic Surgery, Töölö Hospital, Helsinki University Hospital, University of Helsinki,

Helsinki, Finland.

\title{
BLOOD FLOW IN FREE MICROVASCULAR FLAPS
}

\author{
Fulvio Lorenzetti
}

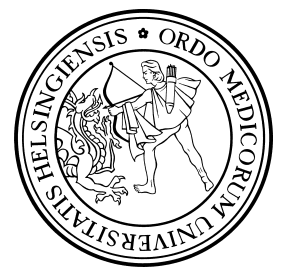


Supervisor: Professor Sirpa Asko-Seljavaara, MD

Department of Plastic Surgery

University of Helsinki

Finland

Reviewers: Professor Zoran Arnez, MD

Department of Plastic Surgery and Burns

University of Ljubljana

Slovenia

Docent Olli Raitakari, MD

Department of Clinical Physiology

University of Turku

Finland

Opponent: Professor Willy Boeckx, MD

Department of Plastic Surgery

University of Maastricht

The Netherlands

ISBN 952-10-0025-2 (nid.)

ISBN 952-10-0026-0 (pdf)

http://ethesis.helsinki.fi

Layout: Callide/Terttu Halme

Helsinki University Press

Helsinki 2001 
To the love of my life, my wife and best friend Rosella, for her love, understanding, and unconditional support 


\section{CONTENTS}

LIST OF ORIGINAL PUBLICATIONS ............................................................ 7

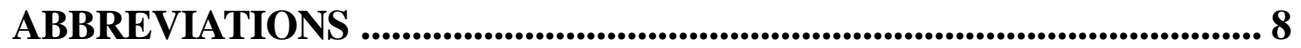

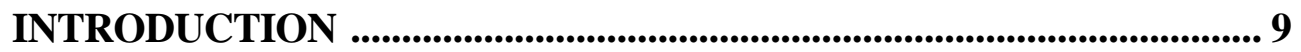

REVIEW OF THE LITERATURE ........................................................ 10

1. Blood flow in muscle, fasciocutaneous and musculocutaneous flaps. 10

1.1 Free muscle flaps .................................................................... 10

1.2 Free muscle flaps and vascular bypass in the lower extremity .. 11

1.3 Free radial forearm flap ...................................................... 13

1.4 Pedicled and free TRAM flap ................................................ 13

2. Transit-time ultrasonic flowmeter ..................................................... 15

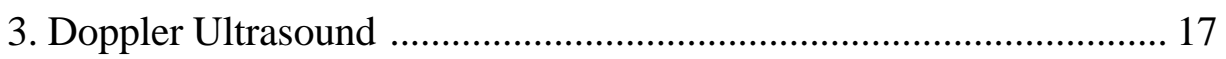

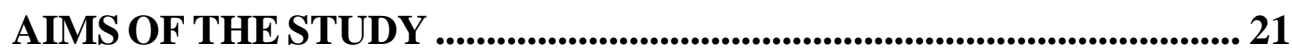

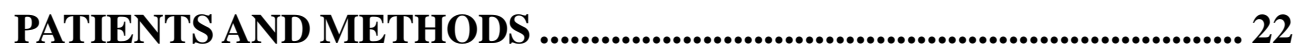

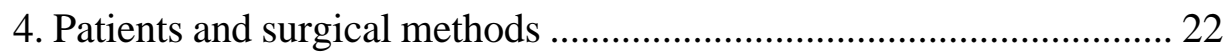

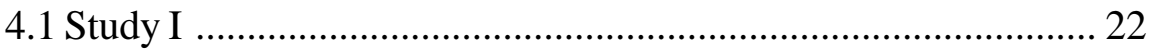

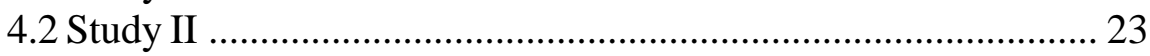

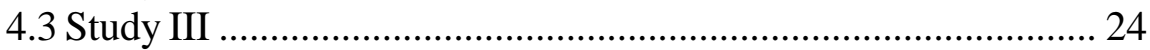

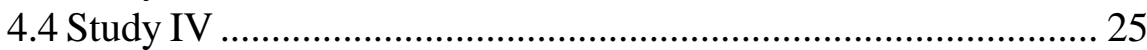

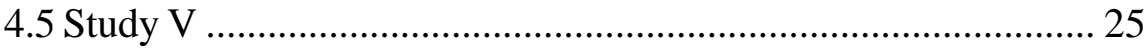

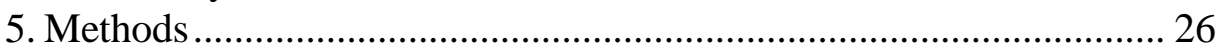

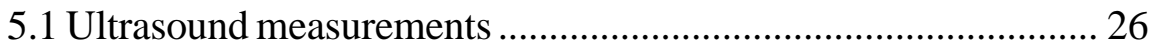

5.2 Transit-time ultrasonic flowmeter measurements ...................... 27

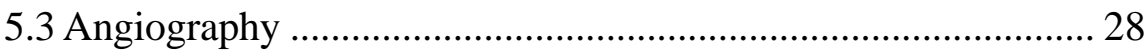

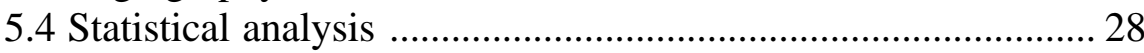

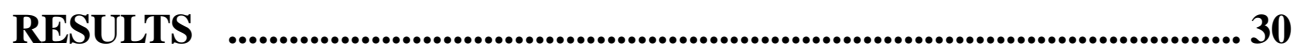

6. Colour Doppler ultrasound measurements ......................................... 30

6.1 Postoperative haemodynamic changes in the free microvascular LD muscle flap and recipient arteries (I) .......... 30

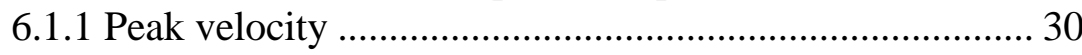

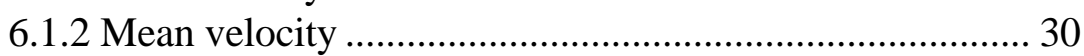

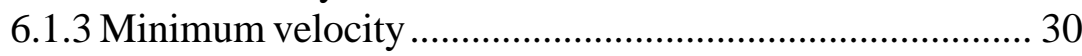

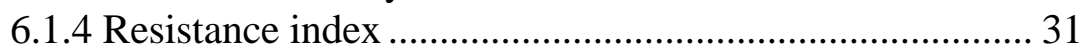

6.1.5 Diameter of the artery ................................................. 31 
6.2 Postoperative haemodynamic changes in the free microvascular TRAM flap and deep superior

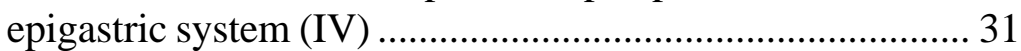

6.2.1 Peak velocity ................................................................ 31

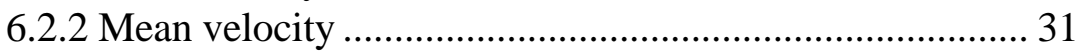

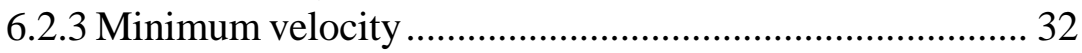

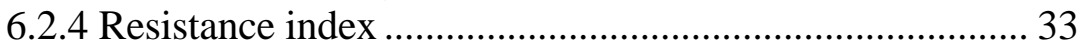

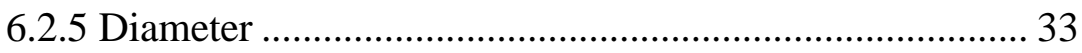

6.3 Postoperative haemodynamic surveillance of bypass and

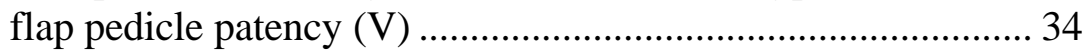

7. Transit-time ultrasonic flowmeter measurements ................................ 34

7.1 Intraoperative haemodynamic changes in different types of free microvascular flaps (II) .............................................. 34

7.2 Intraoperative haemodynamic changes in the free microvascular TRAM flap when anastomosed to either the TD or IM vessels (III) ............................................................. 35

7.3 Intraoperative haemodynamic changes in the limb (bypass and free muscle flap) (V) ............................................................ 36

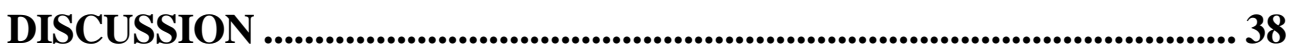

8. Intraoperative blood flow in free flaps .............................................. 38

9. Intraoperative blood flow in free flaps with vascular bypass ........... 40

10. Pre- and postoperative blood flow in free flaps and the recipient sites

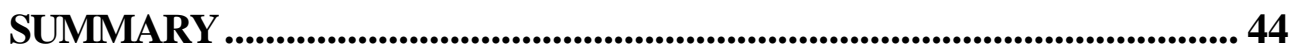

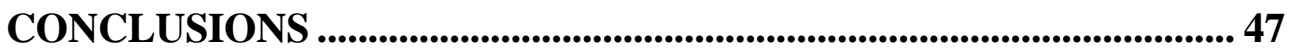

ACKNOWLEDGEMENTS ...................................................................... 49

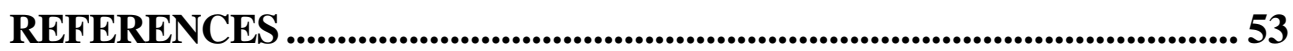

ORIGINAL PUBLICATIONS ........................................................................ 65 


\section{LIST OF ORIGINAL PUBLICATIONS}

The present thesis is based on the following original articles, which are referred to in the text by their Roman numerals.

I Fulvio Lorenzetti, Asko Salmi, Juhani Ahovuo, Erkki Tukiainen, Sirpa Asko-Seljavaara

Postoperative changes in blood flow in free muscle flaps:

a prospective study. Microsurgery 1999;4:196-199.

II Fulvio Lorenzetti, Sinikka Suominen, Erkki Tukiainen, Hannu Kuokkanen, Erkki Suominen, Jyrki Vuola, Sirpa Asko-Seljavaara.

Evaluation of blood flow in free microvascular flaps. Journal of Reconstructive Microsurgery 2001;17:163-167.

III Fulvio Lorenzetti, Hannu Kuokkanen, Karl von Smitten, Sirpa Asko-Seljavaara.

Intraoperative evaluation of blood flow in the internal mammary or thoracodorsal artery as a recipient vessel for a free TRAM flap.

Annals of Plastic Surgery 2001; 46:-......

IV Fulvio Lorenzetti, Juhani Ahovuo, Sinikka Suominen, Asko Salmi, Sirpa Asko-Seljavaara.

Colour Doppler ultrasound evaluation of haemodynamic changes in free TRAM flaps and their donor sites.

Scandinavian Journal of Plastic and Reconstructive Surgery and Hand Surgery (in press, 2001).

V Fulvio Lorenzetti, Erkki Tukiainen, Anders Albäck, Milla Kallio, Sirpa Asko-Seljavaara, Mauri Lepäntalo.

Blood flow in a pedal bypass combined with a free muscle flap. European Journal of Vascular and Endovascular Surgery (in press, 2001). 


\section{ABBREVIATIONS}

$\begin{array}{ll}\text { AK } & \text { Above knee } \\ \text { ANOVA } & \text { Analysis of variance } \\ \text { BK } & \text { Below knee } \\ \text { IMA } & \text { Internal mammary artery } \\ \text { LD } & \text { Latissimus Dorsi muscle } \\ \text { TDA } & \text { Thoracodorsal artery } \\ \text { TFL } & \text { Tensor Fasciae Latae muscle } \\ \text { TRAM } & \text { Transverse Rectus Abdominis Musculocutaneous } \\ \text { RA } & \text { Rectus Abdominis muscle } \\ \text { Ri } & \text { Resistance index }\end{array}$




\section{INTRODUCTION}

In 1958 the replantation of an amputated extremity was attempted in an historic operation by Onji and Tamai in Japan (164) and 2 years later Jacobson and Suarez demonstrated the potential of the microvascular repair of $1 \mathrm{~mm}$ vessels with the aid of a microscope (63) . Thus the microvascular anastomotic technique began to develop. The first clinical application of microsurgery was replantation (18,28). In 1968 Komatsu and Tamai successfully performed a complete digital replantation (77). The first experimental free flap operation was reported by Krizek et al. in 1965 (80), and 6 years later, in 1971, Antia and Buch performed the first free microvascular flap operation in a human (8): a facial defect was reconstructed using a lower abdominal dermolipomatous flap, which unfortunately became partially necrotic. The first completely successful clinical microvascular transfer was of an omental flap, used by McLean and Buncke to fill a large scalp defect (103). In 1973 Daniel and Taylor (31) published a report of the first free skin flap (a groin flap), used to cover a defect in the distal one-third of the lower extremity. A groin flap was also used by O'Brien et al. to reconstruct a large defect in the foot (112). In 1974 Harii et al. reported the successful use of different types of free microvascular flaps (53).

The advent of microsurgery reawakened interest in anatomy, as efforts were made to find new flaps suitable for free tissue transfer $(1,32,105,167-169,188)$. Nowadays many types of flap are available, varying in size, bulk, tissue component (muscle, skin-subcutaneous tissue, muscle-skin, skin-fascia, bowel, omentum or vascularized bone), texture or colour match, depending on the kind of reconstruction to be performed. Free tissue transfers are effective for treating complicated fractures and essential for repairing large soft tissue and bone defects in the limbs, as well as for reconstructing the pharynx or oesophagus, the genitalia, the breast or the chest and abdominal wall. Complex and composite tissue reconstructions, such as neurovascular transfer of sensate skin island or vascularized bone, nerve or tendon are also possible.

Free tissue transfer using microvascular techniques is now an established and reliable method in reconstructive surgery and has become (74) an essential component of the plastic surgeon's armamentarium. However, even if the use of free flaps has become routine practice nowadays, with a success rate of from $95.9 \%$ to $99 \%(58,75,115,146,151,196)$, we still lack in-depth knowledge of free flap pathophysiology.

It is important to study the physiology of different kinds of transplant to obtain valuable information on the type kind of flap that is safest and most reliable, on the clinical events that affect the viability of the transplant and on the influence of the transplant on the haemodynamics of the recipient site and vice versa.

The studies reported here used colour Doppler ultasound and a transit-time ultrasonic flowmeter to investigate blood flow in muscle, osteo-muscle, musculocutaneous and fasciocutaneous flaps as well as in their recipient sites. 


\section{REVIEW OF THE LITERATURE}

\section{Blood flow in muscle, fasciocutaneous and musculocutaneous flaps}

Various techniques and measurements have been used for monitoring free flaps to assess their viability and to permit early surgical intervention, such as tissueoxygen measurement (189), microdyalisis (178), laser Doppler (196), photopletysmography (68), temperature measurement (76), or $\mathrm{pH}$ determination (44).

Several studies have also been conducted to establish the reasons for free flap complications such as haematoma and bleeding $(75,83)$, postoperative thrombosis $(75,79,172)$, flap necrosis $(5,82)$ and flap failure $(69,161)$ but few studies have focused on postoperative haemodynamic changes in the transplanted tissue and their effect on recipient site blood circulation.

\subsection{Free muscle flaps}

Experimental studies on muscle pathophysiology documented that blood flow increases immediately after denervation of the skeletal muscle (23) because of arteriolar vasodilation (24) and increased capillary perfusion $(23,149,187)$. Siemionow et al. attributed the acute increases in arteriolar diameters and red blood cell velocities observed in a cremaster muscle model (island flap) and in a replanted composite-limb-cremaster graft to sympathectomy due to pedicle isolation and to muscle denervation following transection of the genitofemoral nerve $(12,150)$. In skin flaps, too, blood flow increases after denervation because of the decline in vascular resistance $(42,61,102)$. In a new skin island flap in Syrian hamsters, Erni et al. (36) showed higher flow values than in the control after sympathectomy by neural blockade. The most likely cause of this phenomenon was conspicuous vasodilation in the second and third order arterioles, which have the highest density of adrenergic innervation (137) and contribute more than any other microvessels to vascular resistance and flow regulation (119). However, in some other studies, the chemical or mechanical sympathectomy that occurred when the vascular pedicle of the flap with its perivascular sympathetic fibres was cut resulted in a hyperadrenergic state causing vasoconstriction and reduced vascular supply to the flap (72).

Using magnetic resonance imaging (MRI), computer assisted tomography (CT) and colour Doppler ultrasound, Salmi et al. showed in clinical studies that the extensive postoperative swelling of a free muscle flap subsides over time and that the flap regains its original thickness in 6-9 months $(133,134)$ although lower extremity and LD muscle flaps tend to be thicker (132). They also showed that, in the lower extremity, free muscle flaps maintain their vascular pe- 
dicle and seem to have more muscle bulk, probably because of vigorous blood flow through their pedicles and in the muscle tissue itself (132). On the other hand most pedicles could not be found by ultrasound examination in free muscle flaps transplanted to the upper extremity (132). Machens et al. found persistence of pedicle blood flow for up to 10 years after uncomplicated free LD transfer (93) whereas loss of autonomous blood supply through the vascular pedicle, with thrombosis of the venous anastomosis, seems to occur in free tissue transfers even after successful surgical revision (92).

In a clinical haemodynamic study of free muscle flaps transplanted to the lower extremity, with colour Doppler ultrasound used both before and after the operation, it was found that blood flow increased in the flaps at 2 weeks to 3 months after the operation because of reduced vascular resistance of the muscle (132). Sasmor et al. have previously documented that flap vascular resistance regulates the blood supply to the flap (138).

In the lower extremity thousands of complicated fractures and complex wounds and defects of various aetiologies have been successfully treated with free muscle flaps $(7,99,190)$. Muscle flaps fill the dead space and prevent fluid collection $(25,108)$. Increased blood flow through the muscle may help to explain the beneficial effects of such flaps on chronic infections $(96,97)$. Perfused free flaps bring blood supply to the infected area, increasing local oxygen pressure, neutrophil activity and antibiotic delivery and thus promoting wound healing (38). Free muscle flaps have even proved to be effective in preserving infected autogenous vein grafts after radical surgical debridement (175).

\subsection{Free muscle flaps and vascular bypass in the lower extremity}

The use of a free microvascular flap in combination with a vascular bypass has become more common during the last decade. Different types of free flap (omental (100), fasciocutaneous $(48,145)$, myocutaneous $(123)$ and muscle $(87,182))$ have been used together with autogenous vein grafts in critical leg ischaemia patients to cover the bypass and soft tissue defect in an effort to avoid major amputation. A report also exists of the successful use of a free rectus abdominis muscle flap in combination with a long polytetrafluoroethylene bypass in a 69-year-old patient (71). Although the leg salvage rate in operations by this technique ranges from $70 \%$ to $90 \%(48,87,147)$, the effect of a free muscle flap on the haemodynamics of the recipient bypass and recipient site remains controversial. In a series of 30 lower limb revascularizations with simultaneous free flap transfers, Tukiainen et al. observed three cases of long-term leg salvage despite free flap failure (unpublished). On the other hand in one patient in whom a free rectus abdominis muscle flap transplanted to the foot was anastomosed to a lower extremity vascular bypass, flap survival occurred despite occlusion of 
the graft (98). It would seem that during the first postoperative months the free flap promoted indirect revascularization of the ischaemic recipient site (101), thus allowing the foot and the flap itself to survive despite graft occlusion. However, in some cases the free flap has been held responsible for foot necrosis and eventual limb amputation $(109,153)$. The flap may steal blood from the bypass, thus impairing the precarious circulation in the distal part of the lower extremity.

In haemodynamics Poiseuille's law regulates the flow through a conduit:

$$
\mathrm{Q}=\mathrm{P} \pi \mathrm{r}^{4} / 81 \mu
$$

where $\mathrm{Q}$ is flow, $\mathrm{P}$ is perfusion pressure, $\mathrm{r}$ is radius, 1 is length and $\mu$ is viscosity. Flow is directly proportional to perfusion pressure and inversely proportional to resistance. In parallel circuits the total resistance is given by the following formula:

$$
1 / \mathrm{R}_{\text {total }}=1 / \mathrm{R}_{1}+1 / \mathrm{R}_{2}
$$

This implies that when total resistance decreases the flow increases at constant perfusion pressure. This principle is the foundation of the adjuvant arteriovenous $(\mathrm{AV})$ fistula used in bypass surgery to accelerate blood flow in order to keep the graft open (30). Adjuvant AV fistulas are rarely used in autogenous vein grafts (84). They are mainly indicated for synthetic bypass operations $(30,62)$, in which the effect of runoff on patency rates is more obvious (142). For such grafts to stay open, the velocity of blood flow through them needs to be higher than in autologous grafts (139).

In bypass surgery the role of distal runoff on graft patency rates is clear, poor runoff being responsible for both early (2) and late graft failure (78). These considerations highlight the importance of preoperative evaluation of distal runoff when selecting the patients who will benefit from such a procedure. Angiographic grading can provide a functional assessment of the severity of atherosclerosis disease $(114,118)$ and several methods have been used for runoff score $(70,131,192)$. Here, we used the Rutherford revised method (130).

When a free muscle flap is anastomosed to a vascular bypass, a parallel haemodynamic circuit is created and the total resistance is lowered. If, however, vascular resistance is higher in the primary foot circuit than in the parallel flap circuit, then blood flows preferentially through the flap. In patients with a high-resistance distal occlusive disease the free flap may siphon blood off and potentiate distal ischaemic necrosis (153). To avoid this phenomenon, Tukiainen et al. (unpublished) placed an adjuvant AV fistula distally to the microanastomosis of the flap to increase the distal outflow of the bypass. Van Landuyt and coworkers in their series of 20 vascular bypass with free flap operations anas- 
tomosed to the outflow vessel the bypass end-to-side, leaving the distal end of the graft available for free flap pedicle anastomosis (181). However, we still do not know to what extent a free microvascular muscle transplant affects the haemodynamics in the limb or how to select patients in order to avoid this major complication.

\subsection{Free radial forearm flap}

Lower extremity defects can also be reconstructed with free fasciocutaneous flaps $(179,191)$. Such flaps consist of skin, subcutaneous tissue and fascia. They are therefore thinner than muscle flaps and are suitable for restoring the aesthetic contour of the limb when the defect is not deep or irregular. One of the most popular fasciocutaneous flaps is the radial forearm because it is easy to raise, and is versatile and relatively safe $(64,69,113,156)$. The technique was developed in China by Yang et al. in 1978 (154) and soon entered into clinical usage. Based on the radial artery and its concomitant veins or superficial forearm veins (22), it can be raised as a composite flap including vascularized bone, tendons or the lateral antebrachial cutaneous nerve (107). Because of its pliability and good response to radiotherapy the free radial forearm flap is nowadays the first choice for head and neck cancer reconstruction $(26,113,156)$. Several studies have been conducted on donor site morbidity in relation to blood impairment of the hand after radial artery removal. The donor hand can develop thermoregulatory problems (127), and both sympathetic dystrophy (152) and deficient circulation (11) have been advocated as causes of cold intolerance (162). One case of acute ischaemia due to raising of the radial forearm flap was reported by Jones et al. (67). Vascular complications of free flaps, including the radial forearm, were evaluated by Yuen et al. using laser Doppler flowmetry (196). Spectral analysis of photoplethysmograms was also performed to determine radial forearm free flap pedicle vessel patency (155). To our knowledge no studies have been conducted on the rate of blood inflow into such a flap after transplantation to different recipient arteries.

\subsection{Pedicled and free TRAM flap}

Since 1979, when Holmström published the first report on the use of the free abdominoplasty flap for breast reconstruction (59), and 1982, when Hartrampf described the use of the pedicled TRAM flap (57), several anatomic studies have been conducted on vascular supply to the abdominal wall $(16,17,19,105,188)$. The rectus abdominis muscle is nourished by the deep superior and inferior epigastric systems. The deep superior epigastric artery is a branch of the internal thoracic artery; the inferior artery originates from the external iliac artery and usually has two accompanying veins. The deep superior and inferior epigastric arteries run under and within the rectus abdominis muscle and anasto- 
mose cranially to the umbilicus (105). They give off branches to the rectus muscle and supply the abdominal integument through a set of perforators extending through the rectus fascia. The majority of the perforators are located in the paraumbilical region. Anastomotic channels cross the midline in the subdermal plexus connecting the two sides (165). Their blood supply arises predominantly from the deep inferior epigastric artery, which contributes more to the blood supply of the abdominal skin than does the smaller superior epigastric artery (16). The skin paddle of the pedicled TRAM flap is elevated from below the umbilicus as a transverse ellipse including the subcutaneous fat and either the whole rectus muscle or its medial two-thirds (partial muscle harvest), which is dissected up to the level of the sternum. During flap elevation, the deep inferior epigastric vessels are cut and the flap is tunnelled and transposed to its new position as a breast. The flap is nourished by the deep superior epigastric system through the para- and infraumbilical perforators in retrograde fashion by means of the reduced-calibre corkscrew vessels known as "choke vessels" (16). The skin territory of the TRAM flap is divided into four zones, based on the contribution of the blood supply from the pedicle. The axial/ipsilateral side (zones I and III) to the pedicle is well vascularized but blood circulation on the random/contralateral side (zones II and IV) is less reliable $(104,177)$. To ensure better blood flow a double pedicle technique in which both rectus abdominis muscles are included in the flap has been developed (56). Other options are to "supercharge" the flap with an additional microvascular arterial anastomosis in the axilla (195), to "recharge" $(14,15,144)$ the random side by anastomosing the deep inferior epigastric artery on the axial side to the contralateral artery, which must be included in the flap (parasite) with part of the rectus muscle, or to reconstruct the breast after a delay procedure. Several delay procedures have been proposed such as preelevating the island paddle (174), ligation of the dominant arterial supply $(29,166)$, ligation of the deep inferior epigastric artery combined with skin island delay (65) or embolization of the deep inferior epigastric artery (140) before flap transfer. Such procedures have been shown to cause vasodilation within the delayed TRAM flaps in both clinical (29) and experimental studies $(33,106)$.

The free TRAM flap consists basically of the same skin-fat paddle as the pedicled flap and is nourished through the same perforators but in anterograde fashion, with the deep inferior epigastric artery as the vascular pedicle. The inferior epigastric artery is the dominant supplier of blood to the flap. Clinical haemodynamic studies have shown that the free TRAM has more reliable flow $(176,177)$ and less edge necrosis than the pedicled TRAM flap (45) or even the supercharged version (176). A larger portion of tissue can be included in the flap (40) and better aesthetic results can be achieved (45). For these reasons the free TRAM flap has been our first choice for breast reconstruction since December 1990 (160). 
The TRAM flap is by far the most popular method of autologous tissue breast reconstruction $(9,10,27,50,81,163)$. When breasts are reconstructed using the free TRAM flap, the recommended recipient vessels are either the TD $(51,141,148)$ or IM $(35,41,94,111)$.

We prefer TD vessels for the free TRAM flap (110). Those who choose the internal mammary artery (IMA) think that the vessel guarantees better inflow to the flap because of its larger calibre and higher arterial flow rate $(35,111)$. It has been assumed, especially in delayed reconstructions, that scar tissue in the axilla or previous radiotherapy might have damaged the thoracodorsal artery (TDA) and vein (41).

\section{Transit-time ultrasonic flowmeter}

In 1962 Franklin et al. (43) and, two years later, Plass (120) described the first transit time flowmeter. The theoretical basis for transit time flow measurements were described by Drost in 1978 (34). Experimental studies have shown small variability and error of measurement $(55,91,129,194)$, and also in humans this technique has been validated for intraoperative measurement of blood flow (85). The ultrasonic transit-time flowmeter represents the most recent advance in intraoperative flow measurement $(85,184,185)$, and it is now used in coronary and vascular surgery for direct intraoperative measurements of blood flow, pressure, vascular resistance and impedance. Walpoth et al. used this method to assess the quality of vascular reconstruction after carotid thromboendarterectomy (183) and to record blood flow in the IMA before and after anastomosis to a coronary vessel to help assess the success of the bypass. (186). The transit-time flowmeter has also been used to measure the blood flow and peripheral resistance in femorodistal and femoropopliteal reconstructions (90) and to evaluate different types of arteriovenous fistula in patients undergoing haemodialysis access surgery (66).

To our knowledge, no studies have been published on the use of the ultrasonic transit-time flowmeter in microsurgery. By using suitable probes fitting small vessels ( 2 or $3 \mathrm{~mm}$ in diameter), it is possible to study the blood flow through the pedicles and recipient arteries of microvascular flaps. Harris and co-workers used the method to study blood flow in the pedicled TRAM flap (54), indicating that the connections between the deep inferior and superior epigastric arteries were located cranially to the umbilicus area as shown earlier in the anatomical studies of Taylor and co-workers $(16,170)$.

The probe uses two piezoelectric crystals transmitting a pulsed ultrasonic beam with a frequency of 0.75 to $3.7 \mathrm{MHz}$, depending on probe size. The two crystals are placed on the same side of the vessel, and a metal reflector is located on the contralateral side (Fig. 1) (34). 


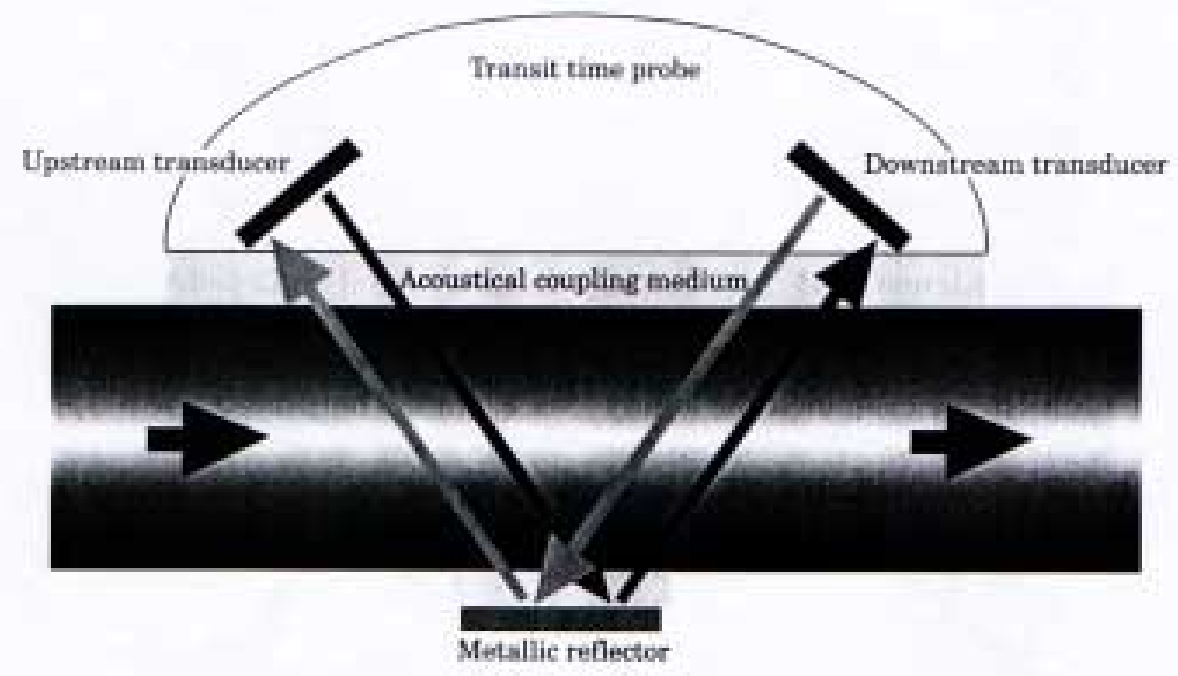

Figure 1. Structure of the transit-time flowmeter probe. From Laustsen et al. (1996), with permission.

The ultrasound beam, which is transmitted from the first crystal through the vessel in an obliquely upstream direction, is reflected from the metal reflector, passes through the vessel a second time and is received by the other crystal. The time between transmission from one crystal and reception at the other, the transit time, is measured and recorded as the phase difference compared with a master oscillator. A second beam is then sent downstream through the vessel in a similar manner. The transmitted wide ultrasonic beam covers the whole width of the vessel lumen, and the transducer integrates all the velocity components inside the vessel. Since non-moving parts within the beam area do not contribute to the flow measurement, the difference between the upstream and downstream transit times is proportional to the volume flow (3).

For the measurements, the probe is placed around the vessel and connected to the ultrasonic flowmeter machine. Minor changes in the angle between the probe and vessel wall do not affect the measurements, which can happen if the vessel is twisted. For this reason the probe must be aligned to the longitudinal axis of the wall (85). The best accuracy is obtained when the probe corresponds well to the outer diameter of the vessel, and acoustic fluid (saline, blood, gel) is present between blood vessel and probe in order to obtain optimal acoustic contact (85). The adequacy of the acoustic contact is checked automatically by the flowmeter and displayed with a colour indicator or numerically (3) (Fig. 2).

The probes are precalibrated by the manufacturer, and so the transit-time flowmeter needs no calibration before the measurements. Neither does the measurement depend on vessel diameter or wall thickness estimations, and it is 


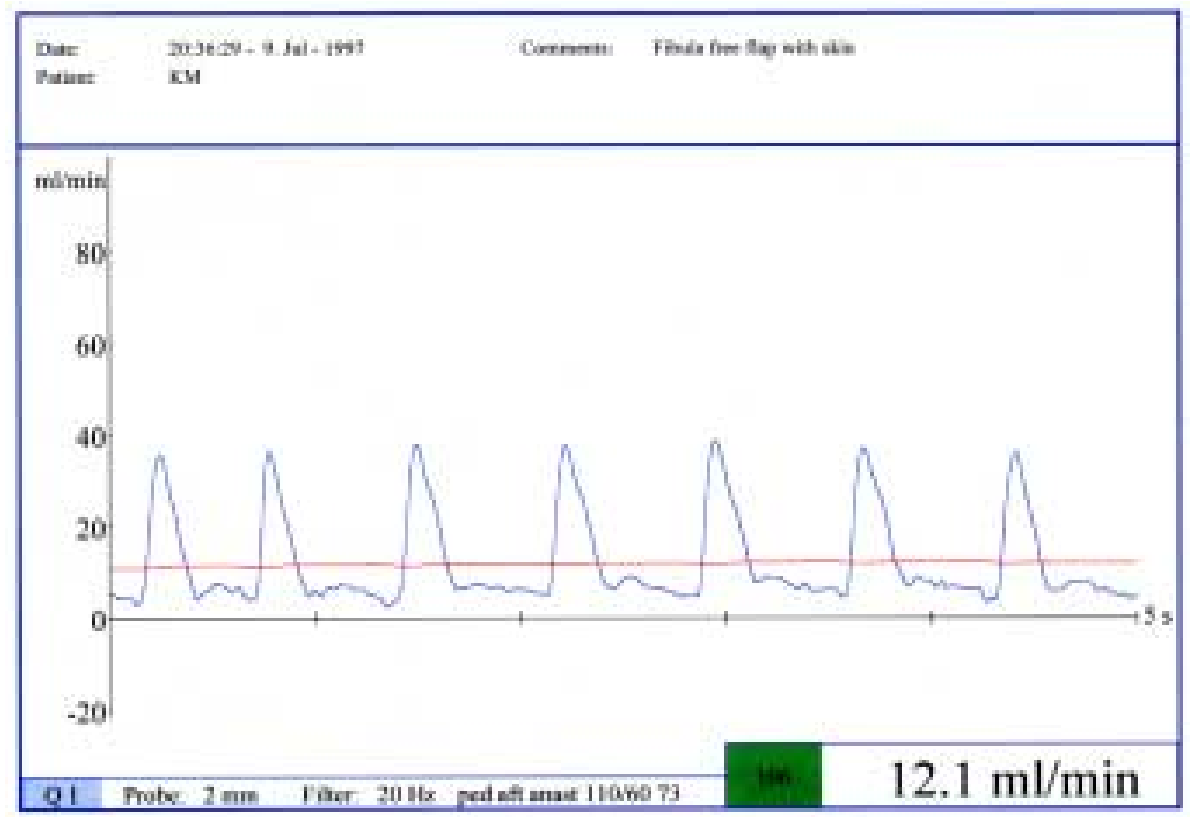

Figure 2. Printout of the flowmeter screen, with curves for pulsatile and mean flow, for the $2 \mathrm{~mm}$ probe. The flow and the acoustic contact are also displayed with a colour indicator and numerically.

insensitive to haematocrit changes (34). Pulsatile and mean flow curves are displayed on the monitor, and the flow $(\mathrm{ml} / \mathrm{min})$ is also presented numerically (Fig. 2). The second generation of transit time flowmeters allows the flowmeter to be connected to a personal computer, which gives unlimited possibilities for data storage and output modalities.

The transit time technique measures blood flow rate $(\mathrm{ml} / \mathrm{min})$ directly, and needs no additional information on the angle of the incident ultrasound wave, vessel diameter or wall thickness $(34,85)$.

\section{Doppler Ultrasound}

Doppler ultrasound is a recent non-invasive technique which has been widely applied in clinical medicine to provide information on blood circulation (143). It can be used to measure vessel patency, and the direction and velocity of blood flow $(116,143,197)$. The technique can accurately distinguish veins from arteries and detect different vascular pathologies in different arteries $(6,49,121,122)$. It is able to detect with good accuracy the presence of stenosis or occlusion (193) and to distinguish aneurysm $(13,20,173)$ or pseudoaneurism $(37,117)$. Using this method we can study haemodynamics not only in large 
vessels but also in small ones with a diameter of less than $2 \mathrm{~mm}$, such as in free flap pedicles $(6,46,60)$.

In free flap surgery Doppler ultrasound has been used to monitor blood flow in a LD free muscle flap (46), to detect vessels (132) and to measure blood flow velocities after free flap surgery (135), indicating that blood flow increases in clinical free muscle flaps from 2 weeks to 3 months postoperatively mainly because of an increase in minimum velocity and a decrease in vascular resistance due to denervation.

The technique has also been used to localize perforators in TRAM flaps $(21,124)$, to precisely localize the pedicle of musculocutaneous gluteus maximus flaps (124) and to monitor the patency of microanastomoses in a microvascular fibula flap (157).

The Doppler principle states that it is possible to evaluate the velocity of a moving object by recording the reflected ultrasound waves (171). By pulsed Doppler technique it is possible to obtain simultaneously a two-dimensional (B-mode) and M-mode image as well and know where the individual target is in relation to the transducer. Peak, mean and minimum velocities of blood flow in vessels can, therefore, be measured. Colour flow imaging is an extension of pulsed Doppler in which colour is introduced to better identify the direction of the flow. Peak velocity is the maximum velocity of erythrocytes towards the ultrasound probe in systole, while minimum velocity corresponds to the lowest velocity in diastole. Using the following formula:

$$
\mathrm{Ri}=\left(\text { Systolic }_{\text {peak velocity }}-\text { Diastolic }_{\text {peak velocity }}\right) / \text { Systolic }_{\text {peak velocity }}
$$

it is possible to calculate the resistance index (Ri) which indicates the resistance of the vessel to blood flow. The diameter of the vessel can also be measured by using ultrasound method (B-mode). Blood flow is directly proportional to blood velocity and inversely proportional to vascular resistance (171); thus at constant blood velocity, flow increases if vascular resistance decreases. The blood flow rate to different tissues varies, depending on their metabolism (47). Organs such as the brain, kidney or liver constantly receive a high percentage of cardiac output and are called "low resistance or impedance" tissues $(47,158)$. 
Muscle and bowel are called "variable resistance" $(47,158)$. tissues as their blood intake depends on their activity. A change from high to low impedance occurs physiologically in the limbs after exercise or in the splanchnic arteries after a meal resulting in increased blood flow (171). Vasodilation lowers vascular resistance and blood flow increases (171). These haemodynamic conditions are shown by two different Doppler patterns. "Low impedance" tissues present a biphasic pattern (Fig. 3), with peak velocity in systole and lower velocity of erythrocytes (minimum velocity) in diastole and yet continuously positive (above the zero line), meaning anterograde flow during the whole diastole (47).

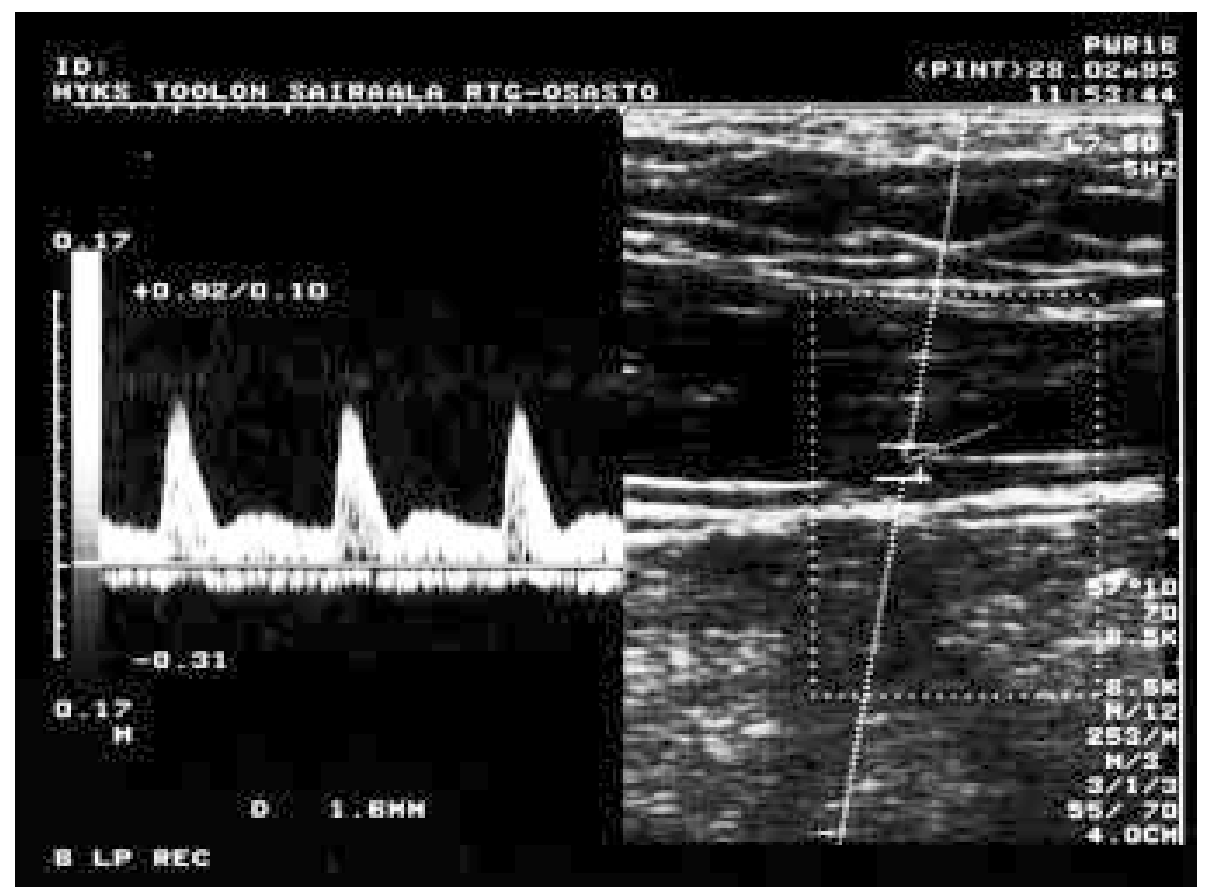

Figure 3. Biphasic pattern, with peak velocity in systole and continuously positive value in diastole (above the zero line), meaning anterograde flow during the whole diastole. 
"High impedance" tissues present a triphasic pattern (Fig. 4): blood velocity being at its maximum in systole (peak velocity) and rapidly decreasing in diastole (minimum velocity), becoming negative for a short period as diastolic pressure cannot overcome the high vascular resistance and blood momentarily flows away from the end organ - not continuously towards it as in the biphasic pattern.

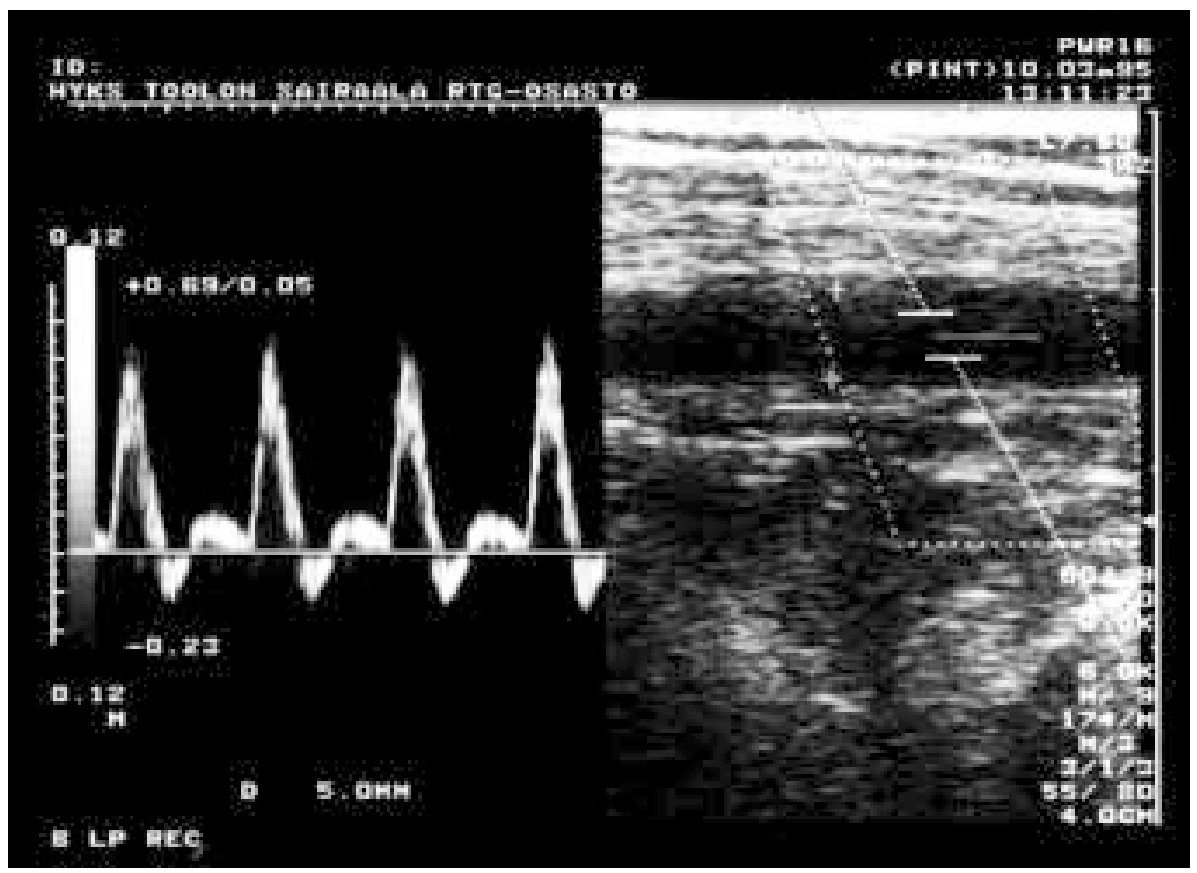

Figure 4. Triphasic pattern, with peak velocity in systole and negative value for a short period in diastole, meaning retrograde flow during the first phase of diastole.

Local obstruction in a vessel is known to cause turbulence and increase blood velocity. It is also known that in small $(<5 \mathrm{~mm})$ vessels - as in this study laminar flow is approached, according to the Reynolds number $(\operatorname{Re}=\mathrm{vd} / v ; \mathrm{v}=$ blood velocity; $\mathrm{d}=$ vessel diameter; $v=$ blood viscosity), which gives reliable figures for blood velocities (171). However, even an expert radiologist must gather a great volume of data to ensure the reliability of the values, as blood circulation is a dynamic, not a static system. The main advantage of this technique is the capability to conduct non-invasive examinations and the easy repeatability of the measurements, making it a useful tool for postoperative surveillance (197). 


\section{AIMS OF THE STUDY}

The study investigated the haemodynamic changes in clinical free microvascular transplants and their recipient sites. It sought to answer the following questions:

- Does blood flow into a microvascular muscle flap increase immediately after surgery? If it does, this could explain the high rate of success of these reconstructive procedures, used to treat, for instance, chronic ulceration and osteomyelites. How does the free flap affect the haemodynamics of the recipient vessel (I)?

- What is the intake of blood taken into different kinds of free flaps and does it depend on the recipient artery flow (II, III)?

- Does the IMA guarantee better blood flow to the free TRAM flap than does the TDA (III)?

- What are the postoperative haemodynamic changes in the abdominal wall and in the free TRAM flap pedicle (IV)?

- What is the haemodynamic effect of a free muscle flap on a revascularized limb subjected to a vascular bypass? Does a free flap impair the critical circulation in the foot and is the flap useful for maintaining graft patency $(V)$ ? 


\section{PATIENTS AND METHODS}

\section{Patients and surgical methods}

One hundred and three patients undergoing free flap surgery at the Department of Plastic Surgery in 1994-1999 took part in these clinical studies. All the studies were approved by the Ethical Committee of Töölö Hospital and the patients gave their informed consent (Table 1).

Table 1. Characteristics of the patients.

\begin{tabular}{llllll}
\hline Study & I & II & III & IV & V \\
\hline Patients, no & 10 & 86 & 25 & 10 & 13 \\
Age, yr & 43 & 52 & 51 & 53 & 58 \\
Mean (range) & $(18-69)$ & $(18-78)$ & $(32-61)$ & $(47-61)$ & $(46-69)$ \\
Female & 2 & 40 & 25 & 10 & 5 \\
Male & 8 & 46 & - & - & 8 \\
Smokers, \% & 40 & 28 & 12 & 10 & 54 \\
Operation in & $1994-95$ & $1997-98$ & $1997-98$ & 1997 & $1997-99$ \\
\hline
\end{tabular}

\subsection{Study I}

In study I, ten patients coming for microvascular LD muscle flap transfer to the lower extremity were studied with colour Doppler ultrasound pre- and postoperatively.

Three patients suffered from hypertension and one from atherosclerosis. Eight patients had complicated fractures, one a large soft tissue defect and one an arteriosclerotic ulceration. The patients were operated on (mean \pm SD) $7 \pm 5$ months after the initial injury. The mean operation time was $272 \pm 90 \mathrm{~min}$, the ischaemia time of the flap $61 \pm 16 \mathrm{~min}$ and blood loss $890 \pm 450 \mathrm{ml}$.

In one patient the recipient vessel was the anterior tibial artery and in nine the posterior tibial artery. One end-to-end and nine end-to-side artery 
anastomoses were performed. In two patients the posterior tibial artery was completely cut and the T-end of the pedicle (thoracodorsal, sub-scapular and circumflex scapular arteries) was anastomosed end-to-end between the two stumps of the recipient vessel.

In eight patients the recipient vein was one of the comitantes, and in two a branch of the great saphenous vein. On the $1^{\text {st }}$ postoperative day, the operation was repeated on one patient because of venous thrombosis. No flap was lost.

Low molecular weight heparin (Fragmin R 2500 or 5000 IU s.c. on the peroperative morning) was administered to two patients and intravenous lowmolecular dextran (Rheomacrodex $\mathrm{R} 500 \mathrm{ml} / 10 \mathrm{~h}$ on days $0-2$ postoperation) to three patients; one patient received both drugs and four neither of them.

In eight patients the leg was supported postoperatively by external fixators, and in two on pillows.

\subsection{Study II}

Eighty-six consecutive patients undergoing free flap surgery took part in this prospective study. The following flaps were raised: 21 microvascular TRAM flaps for breast reconstructions; 18 radial forearm flaps for repair of head and neck tumour excision defects, and 47 free muscle transfers $(20 \mathrm{LD}$ muscle, $8 \mathrm{LD}$ musculocutaneous and $7 \mathrm{LD}$ muscle-scapular bone flaps; 6 rectus abdominis and 5 gracilis muscles, and 1 musculocutaneous vertical rectus abdominis) for head and neck, lower extremity or trunk reconstruction because of trauma, tumour ablation or vascular disease. No flap was lost.

The TRAM flaps, raised for delayed breast reconstruction (muscle-sparing technique (110)), were anastomosed end-to-end to the TDA. Four patients underwent mastectomy (skin sparing) for carcinoma of the breast and immediate reconstruction. The other 17 patients had had mastectomy with axillary dissection 2-22 (mean 6) years earlier. Four patients suffered from asthma and one from hypertension, and one had a systemic connective tissue disease needing continuous antinflammatory therapy.

Ten patients had had previous radiotherapy to both the chest wall and the axillary region and five were taking tamoxifen (Tamofen ${ }^{\mathrm{R}}$, Leiras, Finland) for nodal metastasis found at the primary operation. On the $5^{\text {th }}$ postoperative day, one patient developed an axillary haematoma and partial superficial necrosis of the flap which needed to be removed, and on the same night after the TRAM flap procedure, a reoperation was performed on two patients who developed venous thrombosis.

The radial forearm flaps, raised for reconstruction of head and neck tumour excision defects, were mostly neurosensory fasciocutaneous. The radial 
artery was anastomosed end-to-end using either the facial, superficial temporal or superior thyroid artery as recipient vessel. The cutaneous nerve included in the flap was anastomosed end-to-end to a cutaneous nerve branch in the neck. The donor defects in the forearm were reconstructed with split skin grafts except in one case in which direct closure of the wound was possible. Most patients underwent radiotherapy 3-4 weeks after surgery. Three patients suffered from hypertension and three from diabetes; three were cardiopathic. One patient died on the 2nd postoperative night because of aspiration.

Most of the flaps were LD, either muscle 20), musculocutaneous (8) or osteomuscle (7). The musculocutaneous flaps included a skin paddle overlying the muscle and the osteomuscle flaps a piece of the scapula border $(7-8 \mathrm{~cm}$ long and 3-4 cm wide). Rectus abdominis and gracilis muscle flaps and one musculocutaneous vertical rectus abdominis flap were also studied.

Most of the flaps were anastomosed end-to-side to either the femoral, popliteal artery, anterior or posterior tibial artery or vascular bypass for lower extremity and trunk reconstruction. In the head and neck cases, the facial or the superior thyroid artery was used as end-recipient vessel. End-to-end venous anastomoses were performed in all the flaps.

One patient suffered from asthma, seven from hypertension, thirteen from diabetes and seventeen from atherosclerosis; nine were cardiopathic.

Patients were given a general anaesthetic, which was maintained with nitrous oxide in oxygen and isoflurane. All patients were given $20 \mathrm{ml} / \mathrm{kg}$ (mean $1100 \pm \pm 190$ (SD) $\mathrm{ml}$ ) of $6 \%$ hydroxyethylstarch (Plasmofusin ${ }^{\circledR}$, Leiras, Turku, Finland) and Ringer acetate solution (4 $400 \pm \pm 950 \mathrm{ml}$ ) (Ringersteril, Medipolar, Oulu, Finland) to maintain stable haemodynamics and to achieve mild hypervolaemic haemodilution. Low molecular weight heparin (Fragmin ${ }^{\circledR} 2500$ or 5000 U.I. s.c.) was administered to the patients on the evening preceding the surgery and continued daily until they were mobile. Blood was transfused as needed. The patients' body temperature was kept stable with a warming mattress, by maintaining an ambient room temperature at $24^{\circ} \mathrm{C}$ and by warming the infusion fluids.

\subsection{Study III}

Twenty-five consecutive patients undergoing breast reconstruction with a unilateral free TRAM flap took part in this prospective study. The majority were the same as those in study II. Four new patients were included, and in these the IMA were used instead of the TD vessels as recipients for the free TRAM flap; two of them had undergone both radiotherapy and chemotherapy. No flap was lost. The mean blood loss was $1245 \mathrm{ml}$ with a range from $500 \mathrm{ml}$ to $3000 \mathrm{ml}$. Free flap ischaemia time was $71 \pm 25 \mathrm{~min}$. 
The free TRAM flaps were raised using the "muscle-sparing technique" $(10,110)$, in which a strip of rectus muscle $(5 \mathrm{~cm}$ long and $2 \mathrm{~cm}$ wide) with a 2.5 -cm-wide strip of anterior rectus sheath, sparing the lateral and medial border of the muscle, is added to the axial side of the flap. The TRAM flap was tailored in the shape of the new breast while still on the abdomen and nourished by the deep inferior epigastric system. After the flap transfer, the fascia was closed with overlapping by 6-8 $\mathrm{mm}$. Two or three sutures plicating the contralateral rectus fascia were used to medialize the umbilicus. (160)

In 21 patients, the flap was anastomosed end-to-end to the thoracodorsal artery (II, III, IV) and in four to the internal mammary artery (III), which was exposed by resecting the fourth costal cartilage.

\subsection{Study IV}

Study IV comprised ten of the 21 patients in study II undergoing delayed breast reconstruction with a unilateral free microvascular TRAM flap. The TD vessels were used as end-recipient vessels in all cases. All patients had had mastectomy with axillary dissection a mean of 6 (range 1-13) years earlier. Six patients had had previous radiotherapy to both the chest wall and axillary region and four took tamoxifen (Tamofen ${ }^{\mathrm{R}}$, Leiras, Finland) for nodal metastasis found at the primary operation. The patients were mainly healthy: none suffered from diabetes, hypertension or cardiac disease.

A reoperation was performed on one patient on the same night after the microsurgical procedure because of venous thrombosis, but no flap was lost.

\subsection{Study V}

During a study period of 29 months (from August 1997 through July 1999) 309 patients with chronic critical leg ischaemia (European Consensus criteria) (39) underwent infrapopliteal bypass at the Department of Vascular Surgery of Helsinki University Central Hospital. The majority (235) had gangrene or tissue loss, in 13 of them to the extent that a free microvascular muscle flap was simultaneously raised to cover the bypass and the soft tissue defect. Most of these cases were also included in study II. A femoropedal bypass operation was performed in ten patients and a popliteopedal bypass in three. All the grafts were done with autogenous veins except one, which used a composite PTFE/saphenous vein. In eleven cases a microvascular LD muscle flap reconstruction was performed; in one case a microvascular rectus abdominis (RA) muscle flap and in one a microvascular tensor fasciae latae (TFL) muscle flap. The arterial pedicle of the flap was anastomosed end-to-side to the vascular bypass and the vein of the pedicle end-to-end to a nearby concomitant vein. All patients were permanently on ASA $100 \mathrm{mg} /$ day orally. Ten patients were dia- 
betic and four had coronary heart disease. Seven patients suffered from hypertension. One uremic patient was on long-term dialysis and one had a functioning kidney transplant. All patients were systematically heparinized during the operation prior to cross clamping for vascular reconstruction. The mean blood loss was $3062 \mathrm{ml}$ with a range from $2000 \mathrm{ml}$ to $4500 \mathrm{ml}$. This massive blood loss was due to the fact that actually three operations were performed simultaneously, i.e. vascular bypass, minor amputation and debridement as well as the harvesting and microsurgical connection of the large free muscle flap, all under uncompromised antithrombotic and anticoagulation therapy. Free flap ischaemia time was $80 \pm \pm 27 \mathrm{~min}$.

\section{Methods}

\subsection{Ultrasound measurements}

All Doppler ultrasound evaluations were performed by the same radiologist using an SSA-27OA/HG (Toshiba Corporation, Japan) diagnostic ultrasound system (duplex scanner) equipped with a 7.5-Mhz linear transducer.

At each time point the peak, mean and minimum velocities as well as the $\mathrm{Ri}$ and diameter of different arteries were recorded. The Ri was calculated using the formula:

$$
\mathrm{Ri}=\left(\text { Systolic }_{\text {peak velocity }}-\text { Diastolic }_{\text {peak velocity }}\right) / \text { Systolic }_{\text {peak velocity }}
$$

In study I the LD pedicle (TDA), recipient artery (anterior or posterior tibial artery) and control artery (contralateral anterior or posterior tibial artery) were investigated on the day before surgery and on the $2^{\text {nd }}, 5^{\text {th }}$ and $10^{\text {th }}$ postoperative days. Preoperatively, the recipient and control arteries were measured in the proximal one third of the leg just below their origins; the point was marked on the skin to give a consistent site for the postoperative measurements. With the patient's arm abducted $\left(180^{\circ}\right)$, the TDA was measured at the point where it enters the muscle and the same point was detected in the flap after transplantation for the postoperative measurements of the pedicle. In the recipient artery the postoperative measurements were made proximally to the microvascular anastomosis on the point previously marked.

In study IV the deep inferior and superior epigastric arteries on both sides and both TDA (the recipient and contralateral) were measured. Baseline values were obtained preoperatively, and the measurements were repeated at 4 to 6 days (first follow-up period) and 15 to 30 days (second follow-up period) postoperatively.

The deep inferior epigastric arteries were measured at the point where they entered the rectus muscle; the superior epigastric arteries along a horizontal line $2-3 \mathrm{~cm}$ caudal to the xifoid process. With the patient's arm abducted $\left(180^{\circ}\right)$, the TDA were measured at the point where they entered the LD muscles. 
After transplantation the skin covering the pedicle was marked to provide a consistent reference point for the postoperative measurements.

In study V colour Doppler ultrasound was used postoperatively to assess the patency of both the bypass and the pedicle of the transplant. The postoperative surveillance was done at 1 week, and at 1, 3 and 6 months or whenever any problems were suspected.

\subsection{Transit-time ultrasonic flowmeter measurements}

The intraoperative measurements were performed with a standard transit-time ultrasonic flowmeter, CardioMed 4000 (Cardiomed AS, Oslo, Norway), provided with three channels allowing simultaneous measurement of three vessels.

The diameter of the probes used was 2-8 $\mathrm{mm}$ depending on the vessel size. The blood flow values were recorded after 20-30 min, waiting for a steady curve of flow. Heart rate, and systolic and diastolic arterial pressure were measured simultaneously.

In studies II and III blood flow was first recorded in the donor artery before the flap was raised. The TRAM pedicle was exposed by a $15-\mathrm{cm}-$ long horizontal incision through the skin and subcutaneous tissue on the axial side along the inferior border of the skin paddle of the flap (II, III). The pedicle was exposed after the fascia had been opened vertically below the arcuate line. The deep inferior epigastric artery was carefully skeletonized at the lateral edge of the RA muscle and the first measurement was made. The same method was used in the RA muscle flaps except that a vertical skin-subcutaneous incision was made (II). The LD and gracilis pedicles were exposed through a skin and subcutaneous incision along the longitudinal axis of the muscle (II). The radial artery was isolated by a 4-cm-long skin incision along the radial border of the forearm flap (II). In the recipient artery, the blood flow value was recorded before the flap was transferred. The last measurement was performed in the flap pedicle after transplantation. Each flap was weighed before transplantation and the blood flow rate $(\mathrm{ml} / \mathrm{min})$ per $100 \mathrm{~g}$ of tissue was calculated.

In study III the first measurement of the TRAM flap donor artery was performed as described above. When the flap was completely raised but still connected to the inferior epigastric vessels the second measurement was performed, setting the probe around the artery at the same place as for the first measurement. At the same time the second team prepared the recipient site, and the recipient vessels (TD or IM) were accurately exposed and blood flow was measured in the artery. The blood flow in the pedicle was also recorded $30 \mathrm{~min}$ after circulation had been reestablished at the chest wall.

In study $\mathrm{V}$ the measurements were made in the bypass before and after the transplantation. Blood flow was also measured in the pedicle of the flap after free flap transplantation. The flow measurements were made 20-30 min after 
opening the flow when the curve on the screen was steady and papaverine had been administered to eliminate vessel spasm.

\subsection{Angiography}

Selective angiography was performed in all patients (V) before the operation to evaluate the extent of arterial disease and to choose the appropriate in-flow and outflow vessels. The preoperative angiographic findings of the run-off vessels (distal run-off) were grading according to the revised version of the ad hoc scoring system proposed by Rutherford et al. (130) (Table 2 and 3).

This scoring scheme assigns a "resistance value" to each outflow artery: 0 to normal run-off arteries, and 3 to maximum resistance arteries (Table 3). Depending on the normal proportional contribution to out-flow, each of the vessels is also assigned a weighting unit of 1,2 or 3 . Each resistance value and its corresponding weighting unit are multiplied and a value of 1 is added to the sum of all such products, because even a widely patent run-off bed offers some resistance. This gives a total score of from 1 to 10 , where 1 is a widely patent run-off and 10 is a totally occluded segment (Table 2).

\subsection{Statistical analysis}

In studies I and IV statistical analyses were performed by the Friedman twoway analysis of variance test and the multiple comparisons test, using BMDP Statistical Software.

For statistical analysis in study II we used repeated measures ANOVA to analyse the blood flow values and the changes between donor, recipient and pedicle arteries after anastomosis. Each group of flaps was analysed separately. The analysis was also run separately for different arteries as well as for the flap intake of blood between groups.

In study III the transit-time flowmeter data were evaluated by linear models using previous stage and systolic, diastolic pressure and heart rate values as covariates. Since none of the covariates were significant, the analysis was reduced to paired t-test and t-test. The values of flow in different phases in each group of patients were compared by the paired t-test. The t-test was used to compare blood flow values between the two groups (A and B).

In study $\mathrm{V}$ the transit-time data were evaluated by linear models using previous stage and systolic, diastolic pressure and heart rate values as covariates. Since none of the covariates were significant, the analysis was reduced to the t-test and Wilcoxon signed ranks test, and results were the same.

Probabilities of less than 0.05 were considered significant. Data are expressed as means ( \pm standard deviation). 
Table 2. Calculation of angiogram score of patients undergoing bypass grafting as proposed in the revised version of recommended standards for reports dealing with lower extremity ischaemia (130) (V).

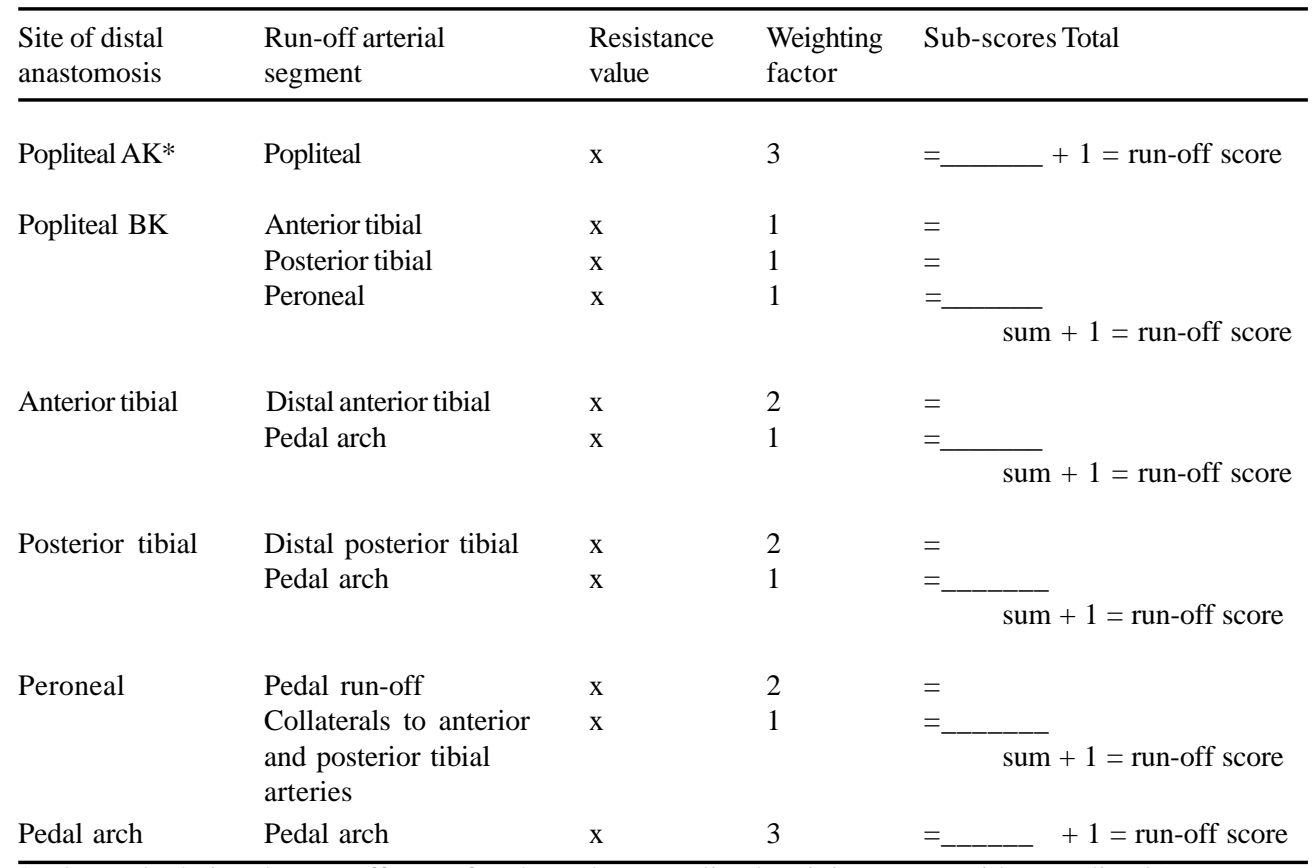

* when calculating the run-off score for above-knee popliteal recipient artery, either popliteal AK or popliteal BK can be used, whichever offers the highest reistance.

Table 3. Resistance values of run-off arteries (130) (V).

\begin{tabular}{|c|c|c|c|c|c|}
\hline $\begin{array}{l}\text { Degree of } \\
\text { occlusion }\end{array}$ & 3 & 2.5 & 2 & 1 & 0 \\
\hline $\begin{array}{l}\text { Major run-off } \\
\text { vessels }\end{array}$ & $\begin{array}{l}\text { Occluded } \\
\text { throughout } \\
\text { lenght }\end{array}$ & $\begin{array}{l}\text { Occluded less } \\
\text { than } 1 / 2 \text { of } \\
\text { lenght; visible } \\
\text { collaterals }\end{array}$ & $\begin{array}{l}50 \% \text { to } 99 \% \\
\text { greatest } \\
\text { stenosis }\end{array}$ & $\begin{array}{l}20 \% \text { to } 49 \% \\
\text { greatest } \\
\text { stenosis }\end{array}$ & $\begin{array}{l}\text { Less than } 20 \% \\
\text { greatest } \\
\text { stenosis }\end{array}$ \\
\hline Pedal run-off & $\begin{array}{l}\text { No primary } \\
\text { pedal artery } \\
\text { patent }\end{array}$ & $\begin{array}{l}\text { Partially patent } \\
\text { or fully patent } \\
\text { beyond critical } \\
\text { in-line } \\
\text { occlusive }\end{array}$ & $\begin{array}{l}\text { In-line } \\
\text { continuity with } \\
\text { patent out-flow } \\
\text { vessel but } \\
\text { incomplete arch } \\
\text { lesion }\end{array}$ & $\begin{array}{l}\text { One or more } \\
\text { subcritical } \\
\text { stenoses } \\
\text { distally but no } \\
\text { in-line }\end{array}$ & $\begin{array}{l}\text { Fully patent } \\
\text { pedal run-off } \\
(<20 \% \text { stenosis })\end{array}$ \\
\hline Pedal arch & $\begin{array}{l}\text { Little or no } \\
\text { arch visualised }\end{array}$ & & $\begin{array}{l}\text { Diseased or } \\
\text { partially } \\
\text { occluded arch }\end{array}$ & $\begin{array}{l}\text { Patent arch } \\
\text { with no } \\
\text { retrograde } \\
\text { out-flow }\end{array}$ & $\begin{array}{l}\text { Completely } \\
\text { patent arch } \\
\text { connecting with } \\
\text { retrograde } \\
\text { flowback into } \\
\text { the other pedal artery }\end{array}$ \\
\hline
\end{tabular}




\section{RESULTS}

\section{Colour Doppler ultrasound measurements}

\subsection{Postoperative haemodynamic changes in the free microvascular LD muscle flap and recipient arteries (I)}

\subsubsection{Peak velocity}

The peak velocity of erythrocytes in the pedicle of free LD muscle flaps increased from the preoperative value during follow-up but not significantly (Table 4). The peak velocity of the recipient artery also increased during follow-up and was significantly higher than the preoperative value on the 5th postoperative day. The peak velocity of the control artery remained the same throughout follow-up.

Table 4. Peak velocity, mean velocity and minimum velocity values $(\mathrm{cm} / \mathrm{sec})$ in the pedicle and in the recipient and control arteries recorded preoperatively, on the $2 \mathrm{nd}$, 5th and 10th postoperative days in free latissimus dorsi flaps to the lower extremity (I).

\begin{tabular}{|c|c|c|c|c|c|c|c|c|c|}
\hline & \multicolumn{3}{|c|}{ Peak velocity } & \multicolumn{3}{|c|}{ Mean velocity } & \multicolumn{3}{|c|}{ Minimum velocity } \\
\hline & Ped. & Recip. & Contr & $\overline{\text { Ped. }}$ & Recip. & Contr & Ped. & Recip. & Contr \\
\hline Preop & $56(24)$ & $79(22)$ & $66(6)$ & $19(8)$ & $14(6)$ & $5(8)$ & $4(5)$ & $-18(9)$ & $-11(14)$ \\
\hline 2nd day & $86(35)$ & $114(36)$ & $85(51)$ & $33(13)$ & $34(17)$ & $12(13)$ & $12(6)$ & $-11(19)$ & $-20(7)$ \\
\hline 5th day & $105(33)$ & $117(37)$ & $65(27)$ & $40(14)$ & $35(16)^{*}$ & $12(9)$ & $19(9)^{*}$ & $-3(19)$ & $-7(7)$ \\
\hline 10th day & $91(38)$ & $81(24)$ & $72(28)$ & $38(17)$ & $23(14)$ & $8(3)$ & $17(10)^{*}$ & $7(11)$ & $-17(5)$ \\
\hline
\end{tabular}

Values are means \pm standard deviation in parentheses.

(differs significantly from preoperative value $(\mathrm{p}<0.05$, Friedman two-way analysis of variance and multiple comparison test)

\subsubsection{Mean velocity}

The mean velocity in the pedicled artery increased from the baseline throughout follow-up but no significant values were found (Table 4). The mean velocity in the recipient artery was significantly higher on the $5^{\text {th }}$ postoperative day. In the control artery it remained the same during follow-up.

\subsubsection{Minimum velocity}

The minimum velocity of the blood flow in the pedicle showed an increase on the $5^{\text {th }}$ and $10^{\text {th }}$ postoperative days ( $\left.\mathrm{p}<0.05\right)$ (Table 4$)$. The minimum velocity in the recipient artery turned positive but the increases were not significant. In the control artery the minimum velocity remained negative (normal) throughout follow-up. 


\subsubsection{Resistance index}

The resistance indices are shown in Table 5.

In the pedicle and the recipient artery the Ri decreased during the examination period and the decrease was significant on the $10^{\text {th }}$ postoperative day. In the control artery the Ri did not change.

Table 5. Resistance index values in the pedicle and in the recipient and control arteries recorded preoperatively, on the $2 \mathrm{nd}$, 5th and $10^{\text {th }}$ postoperative days in free latissimus dorsi flaps to the lower extremity (I).

\begin{tabular}{llll}
\hline & \multicolumn{4}{c}{ Resistance Index } \\
\cline { 2 - 4 } & Ped. & Recip. & Contr. \\
\hline Preop. & $0.92(0.12)$ & $1.23(0.09)$ & $1.15(0.21)$ \\
2nd day & $0.85(0.09)$ & $1.08(0.15)$ & $1.27(0.12)$ \\
5th day & $0.81(0.07)$ & $1.04(0.20)$ & $1.15(0.15)$ \\
Dth day & $0.79(0.08)^{*}$ & $0.88(0.16)^{*}$ & $1.23(0.02)$ \\
\hline
\end{tabular}

Values are means \pm standard deviation in parentheses.

* differs significantly from preoperative value $(\mathrm{p}<0.05$, Friedman two-way analysis of variance and multiple comparison test)

\subsubsection{Diameter of the artery}

The diameters of the pedicle and of the recipient and control arteries did not change (pedicle diameter mean $1.75 \mathrm{~mm}$, SD 0.40; recipient diameter mean $4.91 \mathrm{~mm}$, SD 1.04; control diameter mean $4.65 \mathrm{~mm}$, SD 1.54).

\subsection{Postoperative haemodynamic changes in the free microvascular TRAM flap and deep superior epigastric system (IV)}

\subsubsection{Peak velocity}

The peak velocity did not change in any of the arteries investigated in study IV (deep inferior and superior epigastric arteries on both sides and both TDA during follow-up. The values in all the arteries pooled was $62 \pm 6 \mathrm{~cm} / \mathrm{sec}$ preoperatively, $63 \pm 14 \mathrm{~cm} / \mathrm{sec}$ at the first follow-up period and $63 \pm 13 \mathrm{~cm} / \mathrm{sec}$ at the second follow-up period.

\subsubsection{Mean velocity}

The mean velocity remained the same as the initial value in all the arteries postoperatively except in the recipient TD and ipsilateral deep superior epi- 
gastric arteries (same side as that from which the TRAM flap was raised). In the recipient TDA the mean velocity increased from the initial value of $14.3 \pm 5 \mathrm{~cm} / \mathrm{sec}$ to $34.3 \pm 15 \mathrm{~cm} / \mathrm{sec}(\mathrm{p}<0.05)$ during the second postoperative period. In the ipsilateral superior epigastric artery the mean velocity increased from $17.8 \pm 7 \mathrm{~cm} /$ sec to $26.6 \pm 11 \mathrm{~cm} / \mathrm{sec}(\mathrm{p}<0.05)$ during the first follow-up period and further to $32.8 \pm 11 \mathrm{~cm} / \mathrm{sec}(\mathrm{p}<0.05)$ during the second follow-up period.

\subsubsection{Minimum velocity}

Preoperatively the minimum velocity in the donor deep inferior epigastric artery ranged from -22 to $5 \mathrm{~cm} / \mathrm{sec}$ (mean $-2.2 \pm 9$ (SD) $\mathrm{cm} / \mathrm{sec}$ ) and in the recipient thoracodorsal artery from -12 to $6(0.7 \pm 7) \mathrm{cm} / \mathrm{sec}$. After anastomosis it was significantly higher than the baseline and remained consistently positive during the first $(11.8 \pm 7$ $\mathrm{cm} / \mathrm{sec}$ ) and second follow-up periods $(13.0 \pm 6 \mathrm{~cm} / \mathrm{sec}$ ) (Fig. 5). The same phenomenon was observed in the ipsilateral deep superior epigastric artery: minimum velocity increased $(\mathrm{p}<0.05)$ and remained positive during the first $(11.5 \pm 3 \mathrm{~cm} / \mathrm{sec})$ and second $(13.2 \pm 6 \mathrm{~cm} / \mathrm{sec})$ follow-up periods as compared with the preoperative value $(-0.75 \pm 7 \mathrm{~cm} / \mathrm{sec})$. No significant changes occurred in the control arteries on the side not operated on.

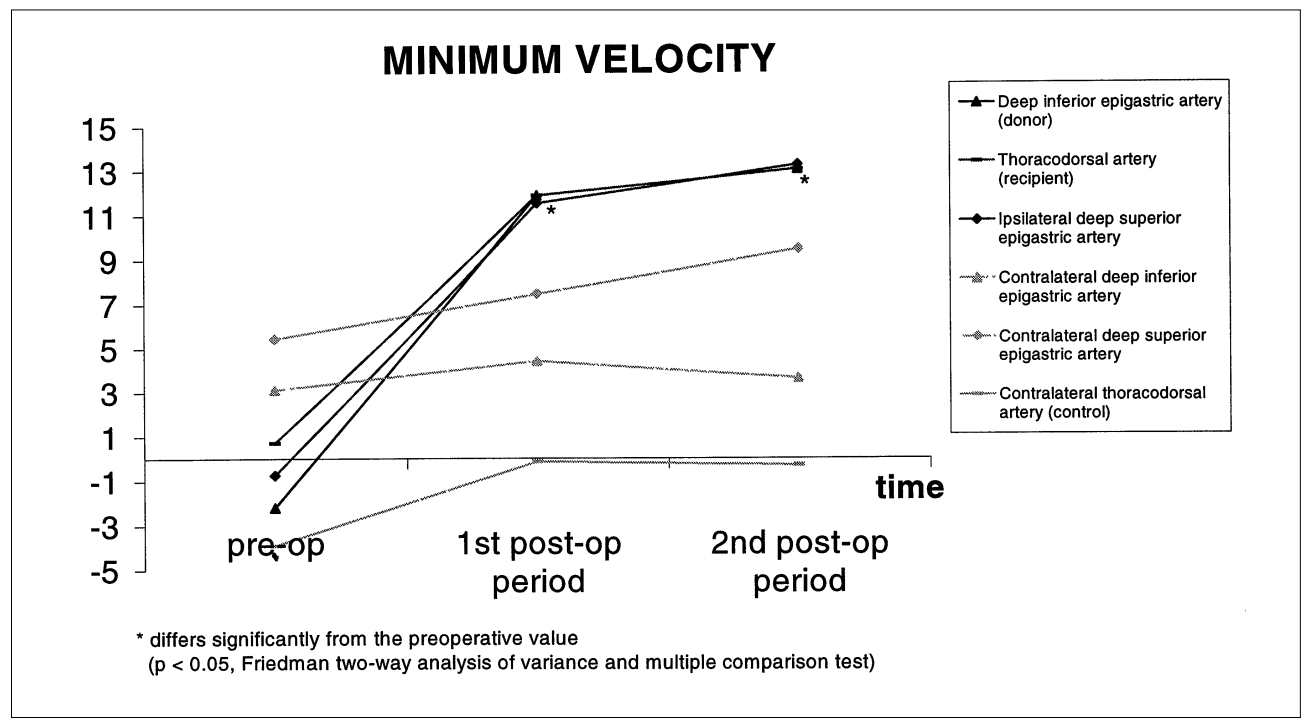

Fig. 5. Mean minimum velocity in different arteries. 


\subsubsection{Resistance index}

After anastomosis the Ri decreased significantly (Fig. 6), being $0.852 \pm 0.111$ at the first and $0.829 \pm 0.054$ at the second follow-up period, whereas it was initially $1.026 \pm 0.127$ in the donor artery. In the deep superior epigastric artery on the ipsilateral side, the index was also significantly lower at both the first $(0.796 \pm 0.067)$ and second $(0.810 \pm 0.087)$ postoperative periods than it had been initially $(0.986 \pm$ $0.101)$. No changes occurred in the control vessels.

\subsubsection{Diameter}

Preoperatively the mean diameter of the donor inferior epigastric and contralateral inferior epigastric arteries was $1.9 \pm 0.1 \mathrm{~mm}$ and was significantly larger than that of the superior epigastric arteries, which was $1.6 \pm 0.2 \mathrm{~mm}$. The vessel diameters did not change after free flap transfer.

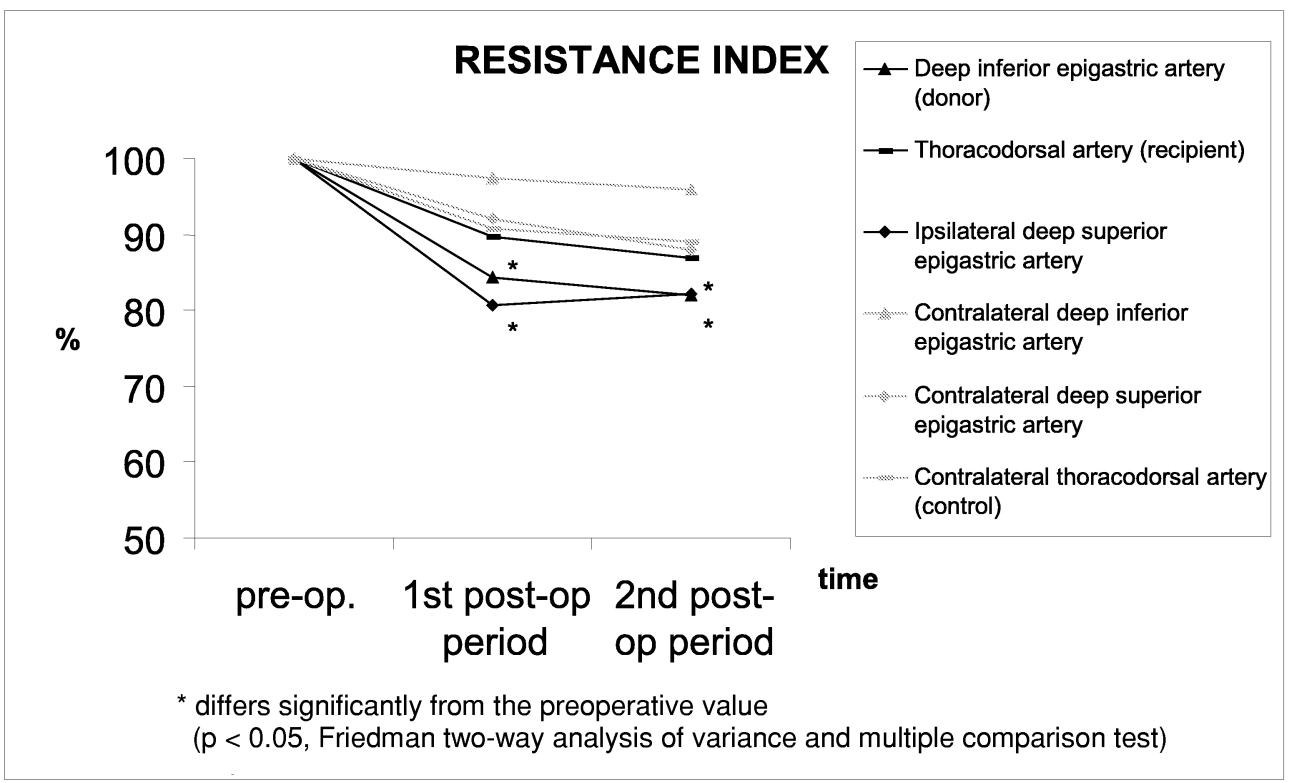

Fig. 6. Percentage changes in the resistance index compared with the initial value. 


\subsection{Postoperative haemodynamic surveillance of bypass and flap pedicle patency $(\mathrm{V})$}

Six months after surgery, colour Doppler ultrasound evaluation showed patency of the bypass and pedicle of the muscle flap in 11 out of 13 patients. Two legs were amputated because of occlusion of the vascular graft and free flap pedicle, one on the $8^{\text {th }}$ and one on the $90^{\text {th }}$ postoperative day.

\section{Transit-time ultrasonic flowmeter measurements}

The patients' heart rate and blood pressure values did not differ from each other at the various phases of the studies.

\subsection{Intraoperative haemodynamic changes in different types of free microvascular flaps (II)}

In study II the flap survival rate was $100 \%$. When the flow in the donor, recipient and pedicled arteries after anastomosis was analysed horizontally within patients, it was found that the radial artery flow dropped $(\mathrm{p}<0.001)$ to one tenth of the initial value when the flap was anastomosed to a neck vessel (Table 6). In contrast, in TRAM flap surgery the recipient artery (TD) showed initially very low flow but after anastomosis the value increased significantly, attaining that of the epigastric artery (Table 6). The flow rate in the TDA of the TRAM flap patients who had scarring due to mastectomy and irradiation was lower than that in the intact TDA of the LD flap patients $(4.9 \pm 3 \mathrm{ml} / \mathrm{min}$ and $17.5 \pm 12$ $\mathrm{ml} / \mathrm{min}$, respectively).

The LD, RA and gracilis muscle flaps were pooled (muscle subgroup) because of their similar values and changes in blood flow. The donor artery flow rate $(14.1 \pm 11 \mathrm{ml} / \mathrm{min})$ was significantly lower $(\mathrm{p}<0.05)$ than the rate after anastomosis $(21.9 \pm 12 \mathrm{ml} / \mathrm{min}$ ) (Table 6). In the musculocutaneous and osteomuscular flaps, although the blood flow value in the donor artery was higher after anastomosis than it had been initially, the increase was not significant, presumably because of the small number of cases in each subgroup (Table 6). An increased blood flow rate $(\mathrm{p}<0.05)$ was found in the muscle flaps pooled $(23.9 . \pm 12 \mathrm{ml} / \mathrm{min}$ and $15.9 \pm 11 \mathrm{ml} / \mathrm{min}$, respectively).

The results of the vertical analyses between different flaps were particularly interesting, as they showed that the flow in the radial artery in the forearm $(57.5 \pm 50 \mathrm{ml} / \mathrm{min})$ was initially at least three times as high $(\mathrm{p}<0.01)$ as in any other donor artery (Table 6).

The flow in the recipient vessels was high and variable, except in the recipient artery (TD) of the free TRAM flap, in which it was lower $(\mathrm{p}<0.001)$ than in the other recipient arteries. 
Table 6. Blood flow in different types of free flaps in donor and recipient arteries as well as in the pedicle artery after anastomosis (II).

\begin{tabular}{|c|c|c|c|c|c|}
\hline \multicolumn{2}{|l|}{ Type of flap } & \multirow{2}{*}{$\begin{array}{l}\text { Donor artery } \\
\mathrm{ml} / \mathrm{min}(\text { mean } \pm \mathrm{SD}) \\
\mathbf{5 7 . 5} \pm \mathbf{5 0}\end{array}$} & \multirow{2}{*}{$\begin{array}{l}\begin{array}{l}\text { Recipient artery } \\
\mathrm{ml} / \mathrm{min}(\text { mean } \pm \mathrm{SD})\end{array} \\
\mathbf{2 8 . 7} \pm \mathbf{1 4}\end{array}$} & \multirow{2}{*}{$\begin{array}{l}\text { After anastomosis } \\
\mathrm{ml} / \mathrm{min}(\text { mean } \pm \mathrm{SD})\end{array}$} & \multirow{2}{*}{$\begin{array}{l}\begin{array}{l}\mathrm{ml} / \mathrm{min} / 100 \mathrm{~g} \\
\text { of tissue }\end{array} \\
\mathbf{1 8 . 5} \pm \mathbf{6}\end{array}$} \\
\hline Radial forearm & $\mathrm{n}=18$ & & & & \\
\hline TRAM & $\mathrm{n}=21$ & $11.3 \pm 6$ & $4.9 \pm 3 *$ & $13.7 \pm 5$ & $2.6 \pm 1$ \\
\hline \multicolumn{6}{|l|}{ Muscle } \\
\hline Muscle & $\mathrm{n}=31$ & $14.1 \pm 11$ & $47.6 \pm 47$ & $21.9 \pm 12 *$ & $10.6 \pm 6$ \\
\hline muscle + skin & $\mathrm{n}=9$ & $22.1 \pm 10$ & $207.5 \pm 72$ & $29.5 \pm 14$ & $7.6 \pm 6$ \\
\hline muscle + bone & $\mathrm{n}=7$ & $15.3 \pm 11$ & $31.1 \pm 32$ & $26.0 \pm 9$ & $8.5 \pm 1$ \\
\hline Total & $\mathrm{n}=47$ & $15.9 \pm 11$ & $69.2 \pm 76$ & $23.9 \pm 12 *$ & $9.7 \pm 6$ \\
\hline
\end{tabular}

$\mathrm{n}=$ number of patients in each group.

Values are means \pm standard deviation.

* differs significantly from initial value $(\mathrm{p}<0.05$, ANOVA test)

After anastomosis, the blood flow rate in the radial forearm flap $(6.1 \pm 2 \mathrm{ml} / \mathrm{min})$ was only one third $(\mathrm{p}<0.01)$ of that in the other flaps, clearly due to the small size of the flap. Blood flow in the pedicle of the free flaps after anastomosing to the recipient sites was compared with the flow rate in the corresponding recipient artery and no correlation was found between the two values, showing that blood flow to the free flap was not dependent on the recipient artery flow.

The weight-adjusted flow through free flaps was highest in the radial forearm flap $(18.5 \pm 6 \mathrm{ml} / \mathrm{min} / 100 \mathrm{~g})$ and significantly different from that in the other flaps $(\mathrm{p}<0.001)$. The flow rate was lowest in the TRAM flap $(2.6 \pm \pm$ $1 \mathrm{ml} / \mathrm{min} / 100 \mathrm{~g}$ ), in which it differed significantly from that in the muscle and radial forearm flaps (Table 6).

\subsection{Intraoperative haemodynamic changes in the free microvascular TRAM flap when anastomosed to either the TD or IM vessels (III)}

The blood flow rate $(\mathrm{ml} / \mathrm{min})$ in different phases of the free TRAM flap operation is shown in Table 7. The rate in the deep inferior epigastric artery before dissection of the flap was $11 \pm 6 \mathrm{ml} / \mathrm{min}$, and did not change after the flap had been raised $(8 \pm 4 \mathrm{ml} / \mathrm{min})$.

The blood flow in the TDA ( $5 \pm 3 \mathrm{ml} / \mathrm{min})$ was significantly lower than in the donor epigastric artery but it increased $(\mathrm{p}<0.05)$ after transplantation up to the initial value of the donor artery $(14 \pm 5 \mathrm{ml} / \mathrm{min})$. The flow rate in the IMA $(25 \pm 10 \mathrm{ml} / \mathrm{min})$ was higher $(\mathrm{p}<0.05)$ than in the donor epigastric artery and TDA but it decreased $(\mathrm{p}<0.05)$ after anastomosis, falling to the 
same level as it was $(12 \pm 3 \mathrm{ml} / \mathrm{min})$ in the donor artery and was the same as after anastomosis in the thoracodorsal site.

Table 7. Blood flow ( $\mathrm{ml} / \mathrm{min})$ measured peroperatively by transit-time flowmeter in different arteries during a free TRAM flap operation (III).

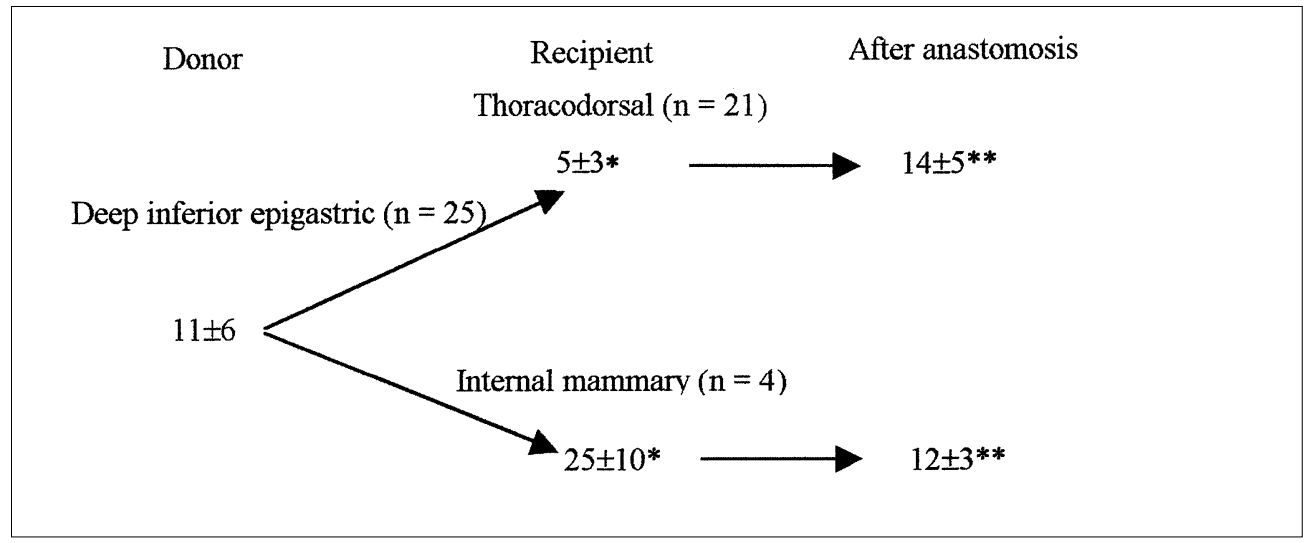

$\mathrm{n}=$ number of patients in each group.

Values are means \pm standard deviation.

$*$ differs significantly $(\mathrm{p}<0.05)$ from donor artery flow.

$* *$ differs significantly $(\mathrm{p}<0.05)$ from recipient artery flow.

\subsection{Intraoperative haemodynamic changes in the limb (bypass and free muscle flap) (V)}

The transit time flowmeter measurements are shown in Table 8.

In the group of patients (11) in whom the leg was salvaged, the mean value of blood flow in the vein graft $(48 \pm 24 \mathrm{ml} / \mathrm{min})$ increased significantly $(\mathrm{p}<0.05)$ after transplantation $(66 \pm 31 \mathrm{ml} / \mathrm{min})$. In this group the blood supply to the foot after transplantation was the same or higher than before transplantation except in case $3(29 \mathrm{ml} v 15 \mathrm{ml})$, case $4(55 \mathrm{ml} v 14 \mathrm{ml})$ and case $5(35 \mathrm{ml}$ vs $14 \mathrm{ml}$ ) presumably because of vessel spasm despite papaverine injection to the proximal graft. Blood flow to the flap was lower than or equal $(34 \pm 11 \%)$ to the distal graft flow.

After transplantation of the free flap blood flow increased in one but did not change in the other vein graft that was to fail. The free flap received $98 \%$ of blood supply through the graft in one case and $69 \%$ in the other. It is interesting that in both of these failures the preoperative angiographic distal runoff was very poor (Table 9). 
Table 8. Blood flow ( $\mathrm{ml} / \mathrm{min})$ in the graft before and after transplantation of the free flap and in the pedicle of the flap after anastomosing to the bypass (V).

\begin{tabular}{lllll}
\hline $\mathrm{n}=13$ & $\begin{array}{l}\text { Graft before } \\
\text { transplantation }\end{array}$ & Graft after transplantation & Pedicle of flap \\
\cline { 3 - 4 } Salvaged & & proximally & distally & \\
\hline 1 & 10 & 60 & 43 & 23 \\
2 & 54 & 105 & 68 & 37 \\
3 & 29 & 35 & 15 & 20 \\
4 & 55 & 20 & 14 & 6 \\
5 & 35 & 25 & 14 & 11 \\
6 & 25 & 64 & 42 & 22 \\
7 & 71 & 99 & 72 & 27 \\
8 & 100 & 113 & 97 & 16 \\
9 & 50 & 75 & 44 & 31 \\
10 & 44 & 67 & 51 & 16 \\
11 & 50 & 64 & 47 & 17 \\
mean & $\mathbf{4 8}$ & & & $\mathbf{2 1}$ \\
SD & $\mathbf{2 4}$ & $\mathbf{6 6}$ & $\mathbf{4 6}$ & $\mathbf{9}$ \\
& & $\mathbf{3 1}$ & $\mathbf{2 6}$ & \\
Amputated & 30 & & & 47 \\
12 & 51 & 48 & 1 & 36 \\
13 & 52 & 14 & \\
\hline
\end{tabular}

$\mathrm{n}=$ number of cases

$\mathrm{SD}=$ standard deviation

Table 9. Preoperative angiographic run-off score according to Rutherford's revised method (1997) (V).

\begin{tabular}{ll}
\hline $\mathrm{n}=13$ & \\
Salvaged & Score \\
\hline 1 & 7 \\
2 & 7 \\
3 & 10 \\
4 & 1 \\
5 & 4 \\
6 & 10 \\
7 & 4 \\
8 & 7 \\
9 & 4 \\
10 & 4 \\
11 & 7
\end{tabular}

\section{Amputated}

$\begin{array}{ll}12 & 10 \\ 13 & 10\end{array}$

$\mathrm{n}=$ number of cases 


\section{DISCUSSION}

\section{Intraoperative blood flow in free flaps}

Despite the high final success rate in free flap surgery (95-99\%), the problem of non-functioning or occluded anastomoses $(73,110,128)$ still exists and although free microvascular flaps are in routine use in reconstructive surgery our knowledge of peroperative blood flow changes in free flaps remains inadequate. Moreover, the effect of a free flap on the recipient vessel flow is poorly understood. Until recently, few methods were available to investigate intraoperative blood flow in human free flaps $(136,176)$. In this work (II, III, V), the haemodynamics of different types of free microvascular flap and recipient vessel was intraoperatively evaluated with the aid of a transit-time ultrasonic flowmeter.

The transit-time ultrasonic flowmeter has been applied in coronary and vascular surgery to give direct intraoperative information on blood flow, blood pressure, vascular resistance and impedance. Validation studies with a transit-time flowmeter show good mutual correlation $(r=0.99)$ and also the actual flow $(3,85)$ in vessels. The blood flow values we recorded here are similar to those found by Harris et al. (54) in the deep inferior epigastric artery and by Walpoth et al. in the IMA(186). All these findings suggest that the transit-time flowmeter is a useful and reliable instrument for measuring the blood flow rate, even in small vessels and in microsurgery. Some errors may nonetheless remain. In vascular surgery the spasm of the artery is eliminated by intra-arterial papaverin injection. In free flap surgery we did not use any pharmacological agents; we merely ensured that the measurements were made no earlier than 20 min after dissection of the vessel was finished or the anastomoses were made to give any spasm of the artery time to resolve. We recommend meticulous dissection of the vessel and delicate manoeuvre in locating the small probe around the dissected vessel. It is noteworthy that blood pressure and pulse rate did not affect the measurements.

Study II comprised 86 different types of free flap used for head and neck tumour defects, for breast reconstructions (TRAM), for soft tissue sarcoma cases or for lower extremity defects caused by injuries or vascular diseases.

For head and neck defect reconstructions, either the superficial temporal, facial or thyroid superior arteries were selected as recipient vessels, and the anastomoses were always performed end-to-end. The most common flap for these cases was the radial forearm flap. We found that although the blood flow was high in both the donor radial and the recipient arteries before flap harvest, the pedicle flow dropped significantly after anastomosis probably as a result of the small size of the flap. In the TRAM flap, however, the flow was maintained after anastomosis at the same level as it was in the donor inferior epigastric vessel before transfer irrespective of whether the TDA or IMA was used as 
end recipient. The blood flow rate in the recipient TDA was less than half of that in the deep inferior epigastric artery. However, after trans-plantation, the flow in the TDA increased significantly despite previous mastectomy and radiotherapy, which might have affected its haemodynamics. Blood flow increases in the TDA most probably because the flap, with its large vascular bed, reduces vascular resistance in the TD end-recipient artery.

The blood flow rate in the IMA was initially much higher (5-fold) than in the TDA but returned to the same level as initially in the deep inferior epigastric vessel, indicating that the IMA does not guarantee better inflow to the flap than does the TDA (III). On the contrary, it seems that a free TRAM flap, which is a musculocutaneous flap with little muscle and a large adipose tissue component, is incapable of taking in more blood than at a rate of 10-20 ml/min and that, moreover, the flow is independent of the recipient artery flow and therefore even a low flow recipient artery is a suitable vessel for a free TRAM flap (II, III).

According to our results in study II, after transplantation the adipose tissue tends to have lower blood supply than muscle tissue. The haemodynamic pattern was similar in flaps containing a large amount of muscle (muscle, musculocutaneous or osteomuscle): blood flow increased intraoperatively after anastomosis, most likely because of the decrease in vascular resistance due to muscle denervation. Several studies have shown that blood flow increases in a denervated muscle $(23,88,135,149,187)$. Sympathectomy relieves arteriolar vasoconstriction $(23,42,61,149,187)$ leading to arteriolar vasodilation with increased capillary perfusion $(23,149,187)$. Vasodilation is also due to loss of muscular tone after denervation. These findings were confirmed in our further study on LD muscle flaps, in which we showed that the intraoperative transit-time flow increased significantly in the pedicle immediately after the thoracodorsal nerve had been cut (89). Increased blood flow might explain some of the known beneficial effects of free muscle flaps on wound healing and chronic infections $(96,97)$.

We did not find any correlation between the flow rates in the recipient artery and in the pedicle of free muscle flaps after anastomosis. Thus blood flow is not dependent on the recipient artery flow in either free radial forearm, TRAM or muscle flaps. On the contrary, the free flap seems to regulate the recipient artery flow according to the flap haemodynamic requirements, which presumably depend on the tissue components (vascular resistance) of the flap.

The most important finding in our intraoperative measurements of 86 free flaps is the intake of blood ( $\mathrm{ml} / \mathrm{min} / 100 \mathrm{~g}$ of tissue) in different flap types. The radial forearm flap seems to have the most vigorous intake of blood, being over six times that of the TRAM flap, most likely because the radial forearm flap probably forms a shunt in the recipient area. The TRAM flap, presumably because of its large adipose tissue component, had the lowest intake of blood per $100 \mathrm{~g}$ of tissue. This may explain the tendency of such flaps to develop fat necrosis, especially on the random side (128). The intake of blood in a free flap containing a 
large piece of muscle is 2-4 times that of a TRAM flap.

It would be interesting in the future to compare different surgical techniques such as the TRAM and the perforator (DIEP) flap for breast reconstruction. Transittime measurements would moreover provide an opportunity to study the use of pharmacological agents to increase flow in the pedicle. In such studies, the cardiac output of the patients must be correlated to the flow in the free flap pedicle.

\section{Intraoperative blood flow in free flaps with vascular bypass}

When free flaps are used in conjunction with vascular bypass in the same lower extremity, it is particularly important to take into account our finding that the microvascular transfer might regulate the recipient artery flow resulting in a redistribution of flow.

In study $\mathrm{V}$ the intraoperative mean value of blood flow in the vein graft of the salvaged legs increased by some $50 \%$ after transplantation of the free flap, as the denervated muscle transplant reduced the vascular resistance of the graft. The free flap received one third of the total blood going through the bypass. On the other hand the blood supply to the foot remained the same before and after transplantation, showing that the free flap did not compromise revascularization of the leg. These results suggest that a free muscle flap behaves like a distal AV shunt (181), which has been advocated as a means of intensifying the distal outflow of the bypass in order to improve the patency of very distal bypasses with poor run-off (180). Thus the patency of the infrapopliteal bypass may be enhanced by a microvascular muscle transplant in some cases in which the flow is too low to maintain the patency. This finding is still very preliminary and needs to be substantiated by further data, as contradictory findings suggest that adjuvant AV fistulas do not improve bypass patency (52) and that a bypass can remain open even when flow is minimal (95).

In study $\mathrm{V}$ the two failing grafts had a totally occluded pedal arch and hence poor run-off, which may explain the redistribution of the flow to the flap and the immediate occlusion of the distal graft in one of the patients. Indeed, Albäck et al. (4) have shown that bypasses to pedal arteries have a $10 \%$ patency rate at one year, if the pedal arch is totally occluded. In the successful group, the vascular bed of the foot was good enough to receive a reasonable amount of blood; in contrast, the feet of the amputated legs had a very poor vascular bed that could not compete with the wide vascular reservoir of the denervated free flap. Whether the redistribution of flow was caused by inadequate run-in was not known because peroperative angiography was not systematically performed.

A solution to this phenomenon in patients undergoing bypass surgery combined with the raising of a free flap might be the use of a radial forearm flap instead of a 
muscle flap. Anastomosing the proximal end of the radial artery end-to-side to the vascular bypass and the distal end to a concomitant or superficial vein in the foot, an AV fistula would be formed. This might help to maintain the graft patency and also avoid the massiveredistribution of blood flow to the flap, because blood intake to the radial forearm flap is very low $(5-10 \mathrm{ml} / \mathrm{min})$. In our further studies we shall be using a transit-time flowmeter to investigate this procedure.

\section{Pre- and postoperative blood flow in free flaps and the recipient sites}

Colour Doppler ultrasound, a technique used during the last few years to study free flaps, offers a non-invasive method to monitor the blood flow in flaps before, during and after operations $(6,21,46,124)$. Salmi and coworkers used colour Doppler ultrasound retrospectively. They showed that free muscle flaps operated on 3 - 5 years earlier had a patent pedicle if they had much muscle bulk and that bulky flaps in lower extremities were probably due to persistent, vigorous blood flow in the pedicle (132). It was also prospectively demonstrated that blood flow increases in free muscle flaps from 2 weeks to 3 months postoperatively mainly because of an increase in diastolic flow and a decrease in vascular resistance (135). We investigated the haemodynamic changes in free LD muscle (I) and TRAM flaps (IV) during the very first days after surgery.

The variability in the values of blood flow found in most of the measurements in our studies reflects the variability in a dynamic system such as blood circulation. This haemodynamic variability elicits the main limitation of the ultrasound method. Therefore, to obtain relatively reliable values of blood flow it is necessary to collect repeated measurements to reduce the inter- and intrapersonal variations.

In study I colour Doppler ultrasound was used in ten consecutive patients receiving a free LD muscle flap reconstruction in the lower leg. The blood velocities in the pedicle, recipient and contralateral (control) arteries were monitored before the operation and on the $2^{\text {nd }}, 5^{\text {th }}$ and $10^{\text {th }}$ postoperative days. We found that peak, mean and minimum velocities rose in the pedicle during the follow up period, which might help the microanastomosis to stay open. The most dramatic change was observed in the minimum velocity in the pedicles: it remained positive throughout follow-up, indicating that there was continuous blood flow towards the flap during the first 10 days after surgery. That the blood flow or vascular resistance did not change in the contralateral (control) arteries corroborates our positive findings. The main reason for the increased blood flow seems to have been a decline in vascular resistance at the arteriolar level in the free muscle flap. Sympathectomy, due to muscle denervation, could significantly increase blood flow by relieving arteriolar vasoconstriction 
$(23,42,61,149,187)$. Muscular tone is also lost due to denervation, which facilitates vasodilation. These postoperative colour Doppler data confirmed the intraoperative haemodynamic changes in free muscle flaps which may explain the beneficial effects of such flaps on wound healing and chronic infections $(96,97)$.

A further finding in this study was that the Ri decreased in the recipient artery.

Increased blood flow was also found in the pedicle of the free TRAM flap during the first postoperative month (IV). The fact that blood velocities were repeatable in the control arteries suggests that our measurements were valid and reliable. This was documented in the form of increased minimum velocity and a decreased Ri. The free TRAM flap seems to have different haemodynamic behaviour from the free muscle flap, as the blood flow in the free TRAM flap did not increase during the operation, but did so soon afterwards. Some humoral factors may have been involved, inhibiting relief of the arteriolar vasoconstriction despite denervation of the flap. It is also possible that some time is needed for blood to fill the entire vascular bed of the TRAM flap because of its large adipose tissue component, which may physically interfere with the flow within the flap. A further possibility is that the main mechanism of the immediate increase in blood flow in denervated muscles is the loss of muscle tone whereas sympathectomy effects, which are present in any kind of transplant, need time to show.

In free TRAM flap surgery we found (IV) that, in the ipsilateral deep superior epigastric system, the vascular resistance decreased and the mean as well as the minimum velocity increased after the flap had been harvested. This phenomenon is presumably due to postoperative inflammation and partial denervation of the severed rectus abdominis muscle, which causes vasodilation (159) and consequently increases blood flow (12). An additional explanation is the absence of the inferior epigastric artery, which increases the flow in the superior epigastric system (166).

To enhance blood circulation within the pedicled TRAM flap several delay procedures have been proposed. These include ligation of the inferior epigastric arteries $(29,166)$, ligation of the deep inferior epigastric artery combined with elevation of the skin island (65) and embolization of the deep inferior epigastric artery (140). Such procedures have been shown to cause vasodilation within the delayed TRAM flaps in both clinical (29) and experimental studies $(33,106)$. Dhar and Taylor demonstrated dilation of choke anastomotic vessels in a delayed RA muscle flap in a canine model; the maximal effect occurred after 3 days and dilation was maintained throughout the first postoperative year (33). Our findings are in accordance with theirs. We saw significantly decreased vascular resistance and increased blood flow in the superior epigastric system only 4 to 6 days after the operation. A delay of 4-6 days might therefore be appropriate for a pedicled TRAM flap. It would be interesting to extend the Doppler follow-up to establish whether blood flow is maintained at such a high level during the following months, as shown in some experimental studies (33,106). In 1997 Restifo et al. (125) and Ribuffo et al. (126) used colour Doppler ultrasound independently of one another to study the deep superior epigas- 
tric artery after ligation of the superficial and deep inferior vessels in a delayed TRAM flap reconstruction. After the delay procedure the diameter of the superior epigastric artery had increased. Ribuffo et al. also showed that the Ri of the artery had decreased (126). Our study confirmed the decrease in the Ri, but we did not find any significant change in the diameter of any of the vessels measured. The reason may have been that in their models the deep superior epigastric artery nourished a larger amount of the abdominal integuments than in our study, in which the free TRAM flap had already been harvested.

In this study, we also confirmed with colour Doppler ultrasound that the deep inferior epigastric artery is larger than the superior one and that it is the main pedicle of the TRAM, as previously suggested by Tuominen et al. (177). 


\section{SUMMARY}

Although free flap surgery is in routine use today, little is known of free flap haemodynamics. We do not know how much blood a free flap receives after transplantation, to what extent a free flap affects the recipient artery flow or whether it causes a redistribution of flow when transplanted to the leg. The present thesis consists of five studies dealing with the haemodynamics of different types of free microvascular flap and recipient site.

Intraoperative blood flow was evaluated with a transit-time ultrasonic flowmeter (II, III, V).

In study II 86 free transplants - 21 free TRAM flaps for breast reconstruction, 18 free radial forearm flaps for head and neck reconstructions, and 47 free muscle flaps for head and neck, trunk and lower extremity reconstructions were investigated. Blood flow was measured in the donor and recipient arteries and in the pedicle after anastomosis. Transit-time flow was highest in the intact radial artery before raising the radial forearm flap pedicle $(57.5 \pm 50 \mathrm{ml} / \mathrm{min})$ but dropped ( $\mathrm{p}<0.001)$ to one tenth after anastomosing $(6.1 \pm 2 \mathrm{ml} / \mathrm{min})$. The flow rate was lowest $(4.9 \pm \pm 3 \mathrm{ml} / \mathrm{min})$ in the recipient artery of the TRAM flap but after transplantation it increased significantly $(13.7 \pm 5 \mathrm{ml} / \mathrm{min})$, attaining the level of the flow in the donor artery. In muscle flaps the donor artery flow increased significantly after anastomosis. No correlation was found between the initial value of blood flow in the recipient artery and the blood supply to the corresponding flap after transplantation.

The weight related intake of blood was highest in the radial forearm flap $(18.5 \pm \pm 6 \mathrm{ml} / \mathrm{min} / 100 \mathrm{~g})$ and lowest in the TRAM flap $(2.5 \pm 1 \mathrm{ml} / \mathrm{min} / 100 \mathrm{~g})$.

The study showed that blood flow through a free microvascular flap does not depend on the recipient artery flow. Even low-flow arteries can be used as recipients because the flow increases in response to the free flap requirements. The blood flow through a free microvascular flap presumably depends on the specific tissue components of the flap.

In study III the peroperative blood flow in 21 free TRAM flaps connected to the TD vessels were compared to those anastomosed to the internal mammary (4 cases). Although the blood flow rate in the recipient TD artery was significantly lower $(4.9 \pm \pm 3 \mathrm{ml} / \mathrm{min})$ than in the donor artery it increased $(\mathrm{p}<0.05)$ $(13.7 \pm 5 \mathrm{ml} / \mathrm{min})$ after transplantation. In contrast, the blood flow rate in the intact IM artery $(25.0 \pm 10 \mathrm{ml} / \mathrm{min})$ was significantly higher than in the donor or TD artery and it dropped after anastomosis $(12.0 \pm 3 \mathrm{ml} / \mathrm{min})$ to the same level as in the donor artery.

We concluded that blood supply in a free TRAM flap is independent of the flow in the recipient artery and that TD vessels, although often in a scarred bed and radiated, are as suitable for anastomosing a free TRAM flap as are IM vessels. 
The purpose of study $V$ was to assess the haemodynamic effect of a free muscle flap on the midterm success of a pedal bypass.

A pedal bypass (autogenous vein graft) combined with a free muscle flap was performed in 13 patients with critical leg ischaemia and ulceration in the ankle or foot. The feeding artery of the flap was anastomosed end-to-side to the bypass.

Intraoperative transit-time flow was measured in the vascular bypass before and after transplantation of the flap and in the pedicle of the flap. Colour Doppler was used postoperatively to assess the patency of the bypass and free flap pedicle.

The bypass and flap pedicle were patent in 11 patients 6 months postoperatively. Two grafts were thrombosed and the legs had to be amputated. In the successful group the blood flow rate (mean $\pm \mathrm{SD}$ ) in the bypass was $48 \pm 24 \mathrm{ml} / \mathrm{min}$. It increased $(\mathrm{p}<0.05)$ after the transplantation to $66 \pm 31 \mathrm{ml} / \mathrm{min}$, being $46 \pm$ $26 \mathrm{ml} / \mathrm{min}$ distributed to the foot and $21 \pm 9 \mathrm{ml} / \mathrm{min}$ to the flap. After transplantation blood flow increased in one but did not change in the other vein graft that was to fail. The free flap received most of the blood $47 \mathrm{ml} / \mathrm{min}(98 \%)$ in one case and $36 \mathrm{ml} / \mathrm{min}(69 \%)$ in the second.

Free muscle flaps increase the blood flow in vascular bypasses, thus contributing to graft patency. However, they cause a redidistribution of blood flow to the flap and cause bypass occlusion and failure of both procedures.

In studies I and IV the peak, mean and minimum velocities, resistance index (Ri) and diameter in the donor and recipient arteries of the latissimus dorsi (LD) and TRAM flaps were measured by colour Doppler ultrasound.

In 10 patients undergoing non-innervated free LD muscle transplantations onto lower extremities the measurements were made preoperatively and on the $2^{\text {nd }}, 5^{\text {th }}$ and $10^{\text {th }}$ days after surgery (I). The minimum velocity value in the LD flap pedicle (thoracodorsal artery) was higher $(\mathrm{p}<0.05)$ and turned positive on the $5^{\text {th }}$ and $10^{\text {th }}$ postoperative days than it had been preoperatively (normally negative). Also the value of the Ri was lower $(\mathrm{p}<0.05)$ on the $10^{\text {th }}$ postoperative day.

In the recipient artery the peak and mean velocities were significantly higher $(\mathrm{p}<0.05)$ on the 5th postoperative day than they had been preoperatively. The minimum velocity increased but not significantly. The $\mathrm{Ri}$ was preoperatively $1.23 \pm 0.09$ and $0.88 \pm 0.16(\mathrm{p}<0.05)$ on the $10^{\text {th }}$ postoperative day.

This prospective clinical study demonstrates that blood flow in the pedicle and in the recipient artery of a free muscle flap increases after surgery. This phenomenon may be due to loss of vascular tone and decreased resistance after denervation. Increased blood flow helps to keep the microanastomosis open and also promotes wound healing (I).

In study IV ultrasonography evaluation was performed on ten women undergoing breast reconstruction with a free TRAM flap anastomosed to the TD 
vessels. Both the deep superior and the inferior epigastric arteries and the TD arteries were investigated (on both sides of the body) at $4-6$ and 15 - 30 days postoperatively.

The minimum velocity in the TRAM flap pedicle (deep inferior epigastric artery) increased $(\mathrm{p}<0.05)$ and turned positive on $5^{\text {th }}(11.8 \pm 7 \mathrm{~cm} / \mathrm{sec})$ and $10^{\text {th }}$ $(13.0 \pm 6 \mathrm{~cm} / \mathrm{sec})$ postoperative day, when compared to the preoperative value $(-2.2 \pm 9 \mathrm{~cm} / \mathrm{sec})$. The resistance index decreased in the pedicle $(\mathrm{p}<0.05)$ from $1.03 \pm 0.13$ to $0.85 \pm 0.11$ on $5^{\text {th }}$ and $0.83 \pm 0.05$ on $10^{\text {th }}$ postoperative day. In the ipsilateral superior epigastric artery (same side from which the free TRAM flap was raised) the mean and minimum velocities increased $(p<0.05)$ while the resistance index decreased $(\mathrm{p}<0.05)$ during the first postoperative month. No changes were registered in the contralateral side of the body. In all patients the deep inferior epigastric artery diameter was larger than that of the superior epigastric and remained so after the transfer.

The increase of flow in the superior epigastric system after raising the free TRAM flap supports the idea that the flow in the pedicled TRAM flap can be increased by delaying the flap (e. g. ligating the inferior epigastric artery). 


\section{CONCLUSIONS}

- Blood flow increases in the vascular pedicle of free muscle flaps immediately after transplantation (II) and remains higher than preoperatively at least during the first 10 postoperative days (I). Blood flow also increases in the recipient $\operatorname{vessel}(\mathrm{I})$.

- The radial forearm flap has the lowest blood flow rate among the different flap types studied, probably due to its small size. In contrast, its weight adjusted flow is the highest, suggesting that the radial forearm flap behaves as a shunt (II).

- In the TRAM flap the intraoperative flow does not change after anastomosis when compared with the initial value of flow in the donor inferior epigastric artery. The intake of blood per $100 \mathrm{~g}$ of tissue was the lowest, presumably because of the extensive adipose tissue component of the TRAM flap (II).

- In flaps with a large amount of muscle (muscle, musculocutaneous or osteomuscle), blood flow increased intraoperatively after anastomosis presumably because of a decrease in vascular resistance due to muscle denervation. The intake of blood per $100 \mathrm{~g}$ of tissue was three times that in the TRAM (II).

- The blood supply to a free microvascular flap depends not on the recipient artery flow but more likely on the specific tissue components of the flap (vascular resistance) (II).

- Despite a patient's previous surgery and radiotherapy, the blood flow provided to the free TRAM flap by the TDA (low-flow artery) is equal to that provided by the IMA (high-flow artery), showing that the success of the free TRAM flap does not depend on the recipient artery flow (III).

- Blood flow in the pedicle of a free TRAM flap increases at least from the 4th to 30th postoperative days, presumably due to a postoperative decline in vascular resistance in the flap. Harvesting the free TRAM flap does not affect vascularization of the contralateral RA muscle but it increases the flow in the ipsilateral superior epigastric artery which supports the idea to improve vascularization in a pedicled TRAM flap by cutting the inferior pedicle (delay phenomenon) (IV). 
- When connected to a femorodistal bypass, a free muscle flap increases the distal outflow bed, reduces outflow bed resistance and thus increases graft flow. Increased blood flow may help to maintain the bypass open. If, however, the distal graft to the foot gets occluded due to poor run-off, the outcome of the foot is very poor. Therefore bypass to pedal arteries with occluded arch with or without AV-fistula seems not feasible (V). 


\section{ACKNOWLEDGEMENTS}

These studies were carried out at the Department of Plastic Surgery, Department of Vascular Surgery, Department of Radiology and Breast Unit in the Helsinki University Hospital, Helsinki University.

I wish to express my deepest gratitude to my supervisor, Professor Sirpa Asko-Seljavaara, MD, Head of the Department of Plastic Surgery, who gave me the great opportunity of working with her and her colleagues. The idea of this project came from her and I wish to thank for her enthusiastic guidance and expert advice during all phases of the study. I am infinitively thankful to her for letting me not only do research but also operations and I am deeply indebted for having taught me microsurgery. When she asked me to do a PhD at Helsinki University I felt very much honoured to cooperate with such an internationally recognised scientist and surgeon, and an extremely nice lady whom I shall never cease to admire.

I am much indebted to my chief in Italy, Alessandro Massei, MD, Head of the Department of Plastic Surgery in Pisa, who introduced me to the field of plastic surgery, followed all the phases of my training and showed great enthusiasm for this project. I am forever obliged to him for letting me be away from work to carry out these studies. His patience, wise suggestions and continous support are warmly acknowledged. Back in Pisa I will finally have more time to spend with him and learn from such an experienced and versatile surgeon for whom I have nothing but the greatest admiration.

I wish to express my gratitude to Professor Paolo Santoni-Rugiu, MD who founded the Department of Plastic Surgery in Pisa and was full of enthusiasm for my clinical research in Scandinavia, a part of the world that he knows very well and very much loves. I thank him for his support and encouragement.

I am sincerely greatful to Grazia Salimbeni, MD, for her valuable suggestions and for having selected the Department of Plastic Surgery in Helsinki for my training. I remember with fondness her visit to Finland during my stay and the efforts she made to find the facilities for my proposal.

I express my warmest thanks to Professor Franco Mazzoleni, MD, Head of the Department of Plastic Surgery, Padova University who permitted me to spend one year of my residency programme in plastic surgery abroad. The years spent in Padova with him and his coworkers were invaluable.

The contribution of Professor Francesco Donato Busnelli (Scuola Superiore S. Anna - Pisa University), Member of the National Committee of Bioethics, has been the utmost importance for my career. I do remember his suggestions and encouragement when I finished the Medical School and, more recently, his valuable help and support in realizing the present project.

I owe my warmest thanks to Professor Franco Mosca, Head of the Depart- 
ment of Surgery and Transplantations, Pisa University, Professor Brunello Ghelarducci, Head of the Institute of Physiology, Pisa University, Professor Carlo Flamigni, Head of the Department of Obstetrics and Gynaecology, Bologna University and Member of the National Committee of Bioethics, and Professor Giulia Biagi, Department of Veterinary Medicine, Pisa University for their help and their confidence in me.

I am grateful to the reviewers of this thesis, Professor Zoran Arnez, MD, from the University of Ljubljana, Slovenia, and Docent Olli Raitakari, MD, from the University of Turku, Finland for their constructive opinions and help in completing this manuscript.

I owe my deepest and warmest thanks to my dear friend Docent Erkki Tukiainen, MD, for having taught me microsurgery and shared with me his unique research material and inestimable experience. His help in providing financial support for my stay in Helsinki is greatly acknowledged.

I wish to express my gratitude to Sinikka Suominen, MD, marvellous friend, whose help has been essential in bringing this project to a successful conclusion. She always had time to help me with writing, with solving computer problems and with suggestions for financial support. I also thank for her endless enthusiasm for research, work and life.

I am sincerely thankful to my dear friend, Asko Salmi, MD, whose help and advice were essential at the start of this thesis and whose encouragement gave me the strenght to go ahead.

The collaboration and positive attitude of Docent Karl von Smitten, MD, Head of the Breast Unit, who shared his vast experience in breast cancer treatment is greatly acknowledged.

It has been a privilege to work with Professor Mauri Lepäntalo, MD, Head of the Department of Vascular Surgery, and Anders Albäck, MD, who introduced me to the field of vascular surgery. I thank them for their teaching and constructive criticism.

Many thanks to Juhani Ahovuo, MD, for his extraordinary patience in collecting the Doppler ultrasound data at any time of the day.

I wish also thanks Susanna Kauhanen, MD, for her help and valuable suggestions in doing research.

I wish to express my gratitude to Professor Borje Sundell, MD, for his keen support during this study and for putting the facilities at my disposal.

I sincerely thank Professor Riccardo Mazzola, General Secretary of the European Association of Plastic Surgeons (EURAPS) for his support and the Association for the Young Plastic Surgeon Scholarship of EURAPS.

I am grateful to Timo Pessi M.Sc and Hanna Oksanen M.Sc, for their invaluable help in the statistical analysis. 
The assistance of Eila Nousiainen and Tuija Kolehmainen who were always ready to help me, was invaluable.

I wish to thank my generous friend Jukka Alstela for taking photographs and helping me with the computer.

I am grateful to Gillian Häckli, BA, for her superb knowledge of scientific English and friendly cooperation when revising my manuscripts.

I sincerely thank Fausto Biancari, MD, for his enthusiasm in doing research in Finland and for his valuable suggestions.

I wish to warmly thank the following persons, my colleagues and friends:

Erkki Suominen, MD, for having let me be an active member of his team specializing in microvascular maxillo-facial reconstructions;

Docent Hannu Kuokkanen, MD, for being a patient and meticulous teacher in the performance of free TRAM flap surgery;

Jyrki Vuola, MD, who introduced me to the use of free flaps in the treatment of burns and his wife, plastic surgeon, Pia Saarinen;

Hannu Salo, MD, who kindly let me take part of aesthetic procedures.

Vesa Juutilainen, MD, and Tiina Jahkola, MD for their support and encouragement;

Jorma Rautio, MD, who I shall always remember for the warm welcome he gave me when I first came to Finland. Operating together gave me a great opportunity to learn plastic surgery and him to improve his Italian.

And finally, my dear friend Jyri Hukki, MD, with whom I spent many hours operating on cleft and craniofacial patients, who was always ready to answer my questions on surgery and keen to introduce me to different aspects of Finnish culture which have now become part of me. His very useful advice about the provisions of grants for my project is warmly acknowledged.

All of you, please accept my deep and sincere thanks. In my heart are the glorious days spent together in the countryside around Helsinki, cooking fresh fish by the lake, drinking good wine and enjoying that quintessential Finnish experience - the sauna.

Without the help and support of all my colleagues, nurses and friends at the Department of Plastic Surgery, this work would never have been accomplished. Their contribution to making me feel part of the Helsinki University Central Hospital is cordially acknowledged.

I shall always be grateful to my dear parents, Anna and Dante, for making it possible for me to do whatever I wanted, and for having never-ending faith in me. I also want to thank my sister, Fiorella, and my brother-in-law Riccardo, for their love and encouragement.

My special, deepest and warmest thanks go to my beloved wife, Rosella, for her invaluable help and tireless support. With her I shared this long experience 
in Helsinki, without her I would never have succeeded. I also thank my wounderful son Giovanni for his generous patience and to whom I intend to dedicate more time in the future.

The financial support provided by Consiglio Nazionale delle Ricerche (CNR), Centre for International Mobility (CIMO), Karin and Einar Stroems Foundation, Paulo and Instrumentarium Foundation, Medi-Stim, Helsinki University and EURAPS is gratefully acknowledged.

Helsinki, May 2001

Fulvio Lorenzetti 


\section{REFERENCES}

1. Acland RD, Schusterman M, Godina M, Eder E, Taylor GI, and Carlisle I. The saphenous neurovascular free flap. Plast Reconstr Surg 1981; 67: 763-774.

2. Albäck A, and Lepäntalo M. Immediate occlusion of in situ saphenous vein bypass grafts: a survey of 329 reconstructions. Eur J Surg 1998; 164: 745-750.

3. Albäck A, Makisalo H, Nordin A, and Lepäntalo M. Validity and reproducibility of transit time flowmetry. Ann Chir Gynaecol 1996; 85: 325-331.

4. Albäck A, Roth W, Ihlberg L, Biancari F, and Lepäntalo M. Preoperative Angiographic Score and Intraopera tive Flow as Predictors of the Mid-term Patency of Infrapopliteal Bypass Grafts. Eur J Vasc Endovasc Surg 2000; 20: 447-453.

5. al-Qattan MM. Ischaemia-reperfusion injury. Implications for the hand surgeon. J Hand Surg 1998; 23: $570-573$.

6. Amerhauser A, Moelleken BR, Mathes SJ, Gooding G, Goldstein R, Callen P, and Filly RA. Color flow ultrasound for delineating microsurgical vessels: a clinical and experimental study. Ann Plast Surg1993;30:193-202.

7. Anthony JP, and Mathes SJ. Update on chronic osteomyelitis. Clin Plast Surg 1991; 18: 515-523.

8. Antia N, and Buch V. Transfer of an abdominal dermo-fat graft by direct anastomosis of blood vessels. Br J Plast Surg 1971; 24: 15-19.

9. Arnez ZM, Bajec J, Bardsley AF, Scamp T, and Webster MH. Experience with 50 free TRAM flap breast reconstructions. Plast Reconstr Surg 1991; 87: 470-478.

10. Asko-Seljavaara S. Delayed breast reconstruction. Clin Plast Surg 1998; 25: 157-166.

11. Backman C. Umeå University Medical Dissertations. Cold Finger. Umeå, Umeå University 1993; 363: $1-110$.

12. Banbury J, Siemionow M, Porvasnik S, Petras S, and Zins JE. Muscle flaps' triphasic microcirculatory respon se to sympathectomy and denervation. Plast Reconstr Surg 1999; 104: 730-737.

13. Beissert M, Jenett M, Trusen A, Wittenberg G, Krause U, Gassel HJ, and Hahn D. Asymptomatic aneurysm of the proximal right subclavian artery: a rare ultrasound diagnosis. Eur Radiol 2000; 10: $459-461$.

14. Berrino P, Casabona F, Adami M, and Muggianu M. The "parasite" TRAM flap for autogenous tissue breast reconstruction in patients with vertical midabdominal scars. Ann Plast Surg 1999; 43: $119-126$.

15. Berrino P, and Santi P. Hemodynamic analysis of the TRAM. Applications to the "recharged"; TRAM flap. Clin Plast Surg 1994; 21: 233-245.

16. Boyd JB, Taylor GI, and Corlett R. The vascular territories of the superior epigastric and the deep inferior epigastric systems. Plast Reconstr Surg 1984; 73: 1-14. 
17. Brown RG, Vasconez LO, and Jurkiewicz MJ. Transverse abdominal flaps and the deep epigas tricarcade. Plast Reconstr Surg 1975; 55: 416-421.

18. Buncke HJ. Microsurgery—retrospective. Clin Plast Surg 1986; 13: 315-318.

19. Carramenha e Costa MA, Carriquiry C, Vasconez LO, Grotting JC, Herrera RH, and Windle BH. An anatomic study of the venous drainage of the transverse rectus abdominis musculocutaneous flap. Plast Reconstr Surg 1987; 79: 208-213.

20. Carriero A, Iezzi A, Magarelli N, Filippone A, Merlino B, Ambrosini R, and Bonomo L. Magnetic resonance angiography and colour-Doppler sonography in the evaluation of abdominal aortic aneurysms. Eur Radiol 1997; 7: 1495-1500.

21. Chang BW, Luethke R, Berg WA, Hamper UM, and Manson PN. Two-dimensional color Doppler imaging for precision preoperative mapping and size determination of TRAM flap perforators. Plast Reconstr Surg 1994; 93: 197-200.

22. Chang TS, Wang W, and Hsu CY. The free forearm flap-a report of 25 cases. Ann Acad Med Singapore 1982; 11: 236-240.

23. Chen LE, Seaber AV, Bossen E, and Urbaniak JR. The effect of acute denervation on the microcirculation of skeletal muscle: rat cremaster model. J Orthop Res 1991; 9: 266-274.

24. Chen LE, Seaber AV, and Urbaniak JR. Combined effect of acute denervation and ischemia on the microcirculation of skeletal muscle. J Orthop Res 1992; 10: 112-120.

25. Chen SH, Wei FC, Chen HC, Chuang CC, and Noordhoff MS. Emergency free-flap transfer for reconstruction of acute complex extremity wounds. Plast Reconstr Surg 1992; 89: 882-888.

26. Cho BC, Kim M, Lee JH, Byun JS, Park JS, and Baik BS. Pharyngoesophageal reconstruction with a tubed free radial forearm flap. J Reconstr Microsurg 1998; 14: 535-540.

27. Clugston PA, Gingrass MK, Azurin D, Fisher J, and Maxwell GP. Ipsilateral pedicled TRAM flaps: the safer alternative? Plast Reconstr Surg 2000; 105: 77-82.

28. Cobbett J. Free digital transfer. J Bone Joint Surg 1969; 51B: 677-679.

29. Codner MA, Bostwick J, 3rd, Nahai F, Bried JT, and Eaves FF. TRAM flap vascular delay for highrisk breast reconstruction. Plast Reconstr Surg 1995; 96: 1615-1622.

30. D’Andrea V, Lepantalo M, Kantonen I, Biancari F, Di Matteo FM, Bartolucci R, Spyrou M, and De Antoni E. Adjuvant arteriovenous fistula in infrapopliteal bypasses. G Chir 1998; 19: 117-119.

31. Daniel R, and Taylor G. Distant transfer of an island flap by microvascular anastomosis. Plast Reconstr Surg 1973; 52: 111-117.

32. Daniel RK, Cunningham DM, and Taylor GI. The deltopectoral flap: an anatomical and hemodynamic approach. Plast Reconstr Surg 1975; 55: 275-282.

33. Dhar SC, and Taylor GI. The delay phenomenon: the story unfolds. Plast Reconstr Surg 1999; 20792091.

34. Drost CJ. Vessel diameter-indipendent volume flow measurements using ultrasound. San Diego Biomedical Symposium, 1978. Vol. 17, 299. 
35. Dupin CL, Allen RJ, Glass CA, and Bunch R. The internal mammary artery and vein as a recipient site for free-flap breast reconstruction: a report of 110 consecutive cases. Plast Reconstr Surg 1996; 98: 685-689.

36. Erni D, Sakai H, Tsai AG, Banic A, Sigurdsson GH, and Intaglietta M. Haemodynamics and oxygen tension in the microcirculation of ischaemic skin flaps after neural blockade and haemodilution. Br J Plast Surg 1999; 52: 565-572.

37. Ertürk H, Erden A, Yurdakul M, Çalikoglu Ü, Ölcer T, and Cumhur T. Pseudoaneurysm of the abdominal aorta diagnosed by color duplex Doppler sonography. J Clin Ultrasound 1999; 27: 202-205.

38. Eshima I, Mathes SJ, and Paty P. Comparison of the intracellular bacterial killing activity of leuko cytes in musculocutaneous and random-pattern flaps. Plast Reconstr Surg 1990; 86: 541-547.

39. European. Working Group on Critical Leg Ischaemia. Consensus Document on Chronic Leg Ischaemia. Eur J Vasc Surg 1992; 6 (suppl A: 1-32).

40. Feller AM, Horl HW, and Biemer E. The transverse rectus abdominis musculocutaneous free flap: a reliable alternative for delayed autologous tissue breast reconstruction. Ann Plast Surg 1990; 25: 425-434.

41. Feng LJ. Recipient vessels in free-flap breast reconstruction: a study of the internal mammary and thoracodorsal vessels. Plast Reconstr Surg 1997; 99: 405-416.

42. Finseth F, and Cutting C. An experimental neurovascular island skin flap for the study of the delay phenomenon. Plast Reconstr Surg 1978; 61: 412-420.

43. Franklin DL, Baker DW, and Rushmer RF. Pulsed ultrasonic transit time flowmeter. IRE Transac Bio-Med Electronics 1962; 9: 44-49.

44. Furnas H, and Rosen JM. Monitoring in microvascular surgery. Ann Plast Surg 1991; 26: 265-272.

45. Gherardini G, Arnander C, Gylbert L, and Wickman M. Pedicled compared with free transverse rectus abdominis myocutaneous flaps in breast reconstruction. Scand J Plast Reconstr Surg Hand Surg 1994; 28: 69-73.

46. Giesswein P, Constance CG, Mackay DR, and Manders EK. Supercharged latissimus dorsi muscle flap for coverage of the problem wound in the lower back. Plast Reconstr Surg 1994; 94: 1060-1063.

47. Goddi A, Martinenghi C, and Gorreta L. Eco-Color-Doppler vascolare. C. Rabbia, R. De Lucchi, and R. Cirillo.Le arterie degli arti inferiori. A. Il normale. Torino, Edizioni Minerva Medica 1995; 558-569.

48. Gooden MA, Gentile AT, Mills JL, Berman SS, Demas CP, Reinke KR, Hunter GC, Westerband A, and Greenwald D. Free tissue transfer to extend the limits of limb salvage for lower extremity tissue loss. Am J Surg 1997; 174: 644-648.

49. Grassi CJ, and Polak JF. Axillary and subclavian venous thrombosis: follow-up evaluation with color Doppler flow US and venography. Radiology 1990; 175: 651-654.

50. Grotting JC. Immediate breast reconstruction using the free TRAM flap. Clin Plast Surg 1994; 21 : 207-221. 
51. Hamdi M, Weiler-Mithoff EM, and Webster MH. Deep inferior epigastric perforator flap in breast reconstruction: experience with the first 50 flaps. Plast Reconstr Surg 1999; 103: 86-95.

52. Hamsho A, Nott D, and Harris PL. Prospective randomised trial of distal arteriovenous fistula as an adjunct to femoro-infrapopliteal PTFE bypass. Eur J Vasc Endovasc Surg 1999; 17: 197-201.

53. Harii K, Omori K, and Omori S. Successful clinical transfer of ten free flaps by microvascular anastomoses. Plast Reconstr Surg 1974; 53: 259-270.

54. Harris NRd, Webb MS, and May JW, Jr. Intraoperative physiologic blood flow studies in the TRAM flap. Plast Reconstr Surg 1992; 90: 553-558.

55. Hartman JC, Olszanski DA, Hullinger TG, and Brunden MN. In vivo validation of a transit-time ultrasonic volume flow meter. J Pharmacol Toxicol Methods 1994; 31: 153-160.

56. Hartrampf CR, and Michelow BJ. C.E. Hartrampf. Breast reconstruction with living tissue: the transverse abdominal island flap (TRAM) for breast reconstruction and chest wall reconstruction. New York, Raven Press 1991.

57. Hartrampf CR, Scheflan M, and Black PW. Breast reconstruction with a transverse abdominal island flap. Plast Reconstr Surg 1982; 69: 216-224.

58. Hidalgo DA, Disa JJ, Cordeiro PG, and Hu QY. A review of 716 consecutive free flaps for oncologic surgical defects: refinement in donor-site selection and technique. Plast Reconstr Surg 1998; 102: 722-732.

59. Holmstrom $\mathrm{H}$. The free abdominoplasty flap and its use in breast reconstruction. An experimental study and clinical case report. Scand J Plast Reconstr Surg 1979; 13: 423-427.

60. Hutchinson DT. Color duplex imaging. Applications to upper-extremity and microvascular surgery. Hand Clin 1993; 9: 47-57.

61. Hynes W. The blood-vessels in skin tubes and flaps. Br J Plast Surg 1950; 3: 165-175.

62. Jacobs MJ, Gregoric ID, and Reul GJ. Prosthetic graft placement and creation of a distal arteriovenous fistula for secondary vascular reconstruction in patients with severe limb ischemia. J Vasc Surg 1992; 15: 612-618.

63. Jacobson J, and Suarez E. Microsurgery in anastomosis of small vessels. Surgical Forum 1960; 9: 243-245.

64. Jacobson MC, Franssen E, Fliss DM, Birt BD, and Gilbert RW. Free forearm flap in oral reconstruction. Functional outcome. Arch Otolaryngol Head Neck Surg 1995; 121: 959-964.

65. Jensen JA, Handel N, Silverstein MJ, Waisman J, and Gierson ED. Extended skin island delay of the unipedicle TRAM flap: experience in 35 patients. Plast Reconstr Surg 1995; 96: 1341-1345.

66. Johnson CP, Zhu YR, Matt C, Pelz C, Roza AM, and Adams MB. Prognostic value of intraoperative blood flow measurements in vascular access surgery. Surgery 1998; 124: 729-737.

67. Jones $\mathrm{BM}$, and $\mathrm{O}^{\prime} \mathrm{Brian} \mathrm{CJ}$. Achute ischaemia of the hand resulting from elevation of a radial forearm flap. Br J Plast Surg 1985; 38: 396-397. 
68. Jones NF. Intraoperative and postoperative monitoring of microsurgical free tissue transfers. Clin Plast Surg 1992; 419: 783-797.

69. Jones NF, Johnson JT, Shestak KC, Myers EN, and Swartz WM. Microsurgical reconstruction of the head and neck: interdisciplinary collaboration between head and neck surgeons and plastic surgeons in 305 cases. Ann Plast Surg 1996; 36: 37-43.

70. Karacagil S, Almgren B, Bowald S, and Eriksson I. A new method of angiographic runoff evaluation in femorodistal reconstructions. Significant correlation with early graft patency. Arch Surg 1990; 125: 1055-1058.

71. Kasabian AK, Glat PM, Eidelman Y, Karp N, and Giangola G. Limb salvage with microvascular free flap reconstruction using simultaneous polytetrafluoroethylene graft for inflow. Ann Plast Surg 1995; 35: 310-315.

72. Kay SR, and LeWinn LR. Neural influences on experimental flap survival. Plast Reconstr Surg 1981; 67: 42-48.

73. Khouri RK. Avoiding free flap failure. Clin Plast Surg 1992; 19: 773-781.

74. Khouri RK. Free flap surgery. The second decade. Clin Plast Surg 1992; 19: 757-761.

75. Khouri RK, Cooley BC, Kunselman AR, Landis JR, Yeramian P, Ingram D, Natarajan N, Benes $\mathrm{CO}$, and Wallemark C. A prospective study of microvascular free-flap surgery and outcome. Plast Reconstr Surg 1998; 102: 711-721.

76. Khouri RK, and Shaw WW. Monitoring of free flaps with surface temperature recordings: Is it reliable? Plast Reconstr Surg 1992; 89: 495-499.

77. Komatsu S, and Tamai S. Successful replantation of a completely cut-off thumb. Plast Reconstr Surg 1968; 42: 374-377.

78. Komori K, Yamamura S, Ishida M, Matsumoto T, Kuma S, Eguchi D, Yonemitsu Y, Onohara T, and Sugimachi K. Acceleration of impairment of endothelium-dependent responses under poor runoff conditions in canine autogenous vein grafts. Eur J Vasc Endovasc Surg 1997; 14: 475-481.

79. Komuro Y, Sekiguchi J, Nomura S, Ohmori K, Takasugi Y, and Arai C. Blood coagulation activity during microsurgery. Ann Plast Surg 1998; 40: 53-58.

80. Krizek T, Tani T, Desperez Q, and Kiohn C. Experimental transplantation of composite grafts by microvascular anastomosis. Plast Reconstr Surg 1965; 36: 538-546.

81. Kroll SS. Why autologous tissue? Clin Plast Surg 1998; 25: 135-143.

82. Kroll SS, Gherardini G, Martin JE, Reece GP, Miller MJ, Evans GR, Robb GL, and Wang BG. Fat necrosis in free and pedicled TRAM flaps. Plast Reconstr Surg 1998; 102: 1502-1507.

83. Kroll SS, Miller MJ, and Reece GP. Anticoagulants and hematomas in free flap surgery. Plast Reconstr Surg 1995; 96: 643-647.

84. Kusaba A, Koja K, Uesato T, and Kina M. Tibial artery autogenous in situ vein bypass with adjunctive arteriovenous fistula. J Cardiovasc Surg 1987; 28: 719-722. 
85. Laustsen J, Pedersen EM, Terp K, Steinbruchel D, Kure HH, Paulsen PK, Jorgensen H, and Paaske WP. Validation of a new transit time ultrasound flowmeter in man. Eur J Vasc Endovasc Surg 1996; 12: 91-96.

86. Lepäntalo M, and Mätzke S. Outcome of unreconstructed chronic critical leg ischaemia. Eur J Vasc Endovasc Surg 1996; 11: 153-157.

87. Lepäntalo M, and Tukiainen E. Combined vascular reconstruction and microvascular muscle flap transfer for salvage of ischaemic legs with major tissue loss and wound complications. Eur J Vasc Endovasc Surg 1996; 12: 65-69.

88. Lorenzetti F, Salmi A, Ahovuo J, Tukiainen E, and Asko-Seljavaara S. Postoperative changes in blood flow in free muscle flaps: a prospective study. Microsurgery 1999; 19: 196-199.

89. Lorenzetti F, Tukiainen E, and Asko-Seljavaara S. Intraoperative evaluation of blood flow in free LD muscle free laps. 4th European Conference of Scientists and Palstic Surgeons (ECSPS), Paris, France, 2000.

90. Lundell A, and Bergqvist D. Prediction of early graft occlusion in femoropopliteal and femorodistal reconstruction by measurement of volume flow with a transit time flowmeter and calculation of peripheral resistance. Eur J Vasc Surg 1993; 7: 704-708.

91. Lundell A, Bergqvist D, Mattsson E, and Nilsson B. Volume blood flow measurements with a transit time flowmeter: an in vivo and in vitro variability and validation study. Clin Physiol 1993; 13: 547-557.

92. Machens HG, Mailander P, Pasel J, Lutz BS, Funke M, Siemers F, and Berger AC. Flap perfusion after free musculocutaneous tissue transfer: the impact of postoperative complications. Plast Reconstr Surg 2000; 105: 2395-2399.

93. Machens HG, Pallua N, Pasel J, Mailaender P, Liebau J, and Berger A. Persistence of pedicle blood flow up to 10 years after free musculocutaneous tissue transfer. Plast Reconstr Surg 1998; 101: 719-726.

94. Majumder S, and Batchelor AG. Internal mammary vessels as recipients for free TRAM breast reconstruction: aesthetic and functional considerations. Br J Plast Surg 1999; 52: 286-289.

95. Mannick JA, and Jackson BT. Hemodynamics of arterial surgery in atherosclerotic limbs. I. direct measurement of blood flow before and after vein grafts. Surgery 1966; 59: 713-720.

96. Mathes SJ, Alpert BS, and Chang N. Use of the muscle flap in chronic osteomyelitis: experimental and clinical correlation. Plast Reconstr Surg 1982; 69: 815-828.

97. Mathes SJ, Feng LJ, and Hunt TK. Coverage of the infected wound. Ann Surg 1983; 198: 420-429.

98. Mätzke S, Tukiainen EJ, and Lepantalo MJ. Survival of a microvascular muscle flap despite the late occlusion of the inflow artery in a neuroischaemic diabetic foot. Scand J Plast Reconstr Surg Hand Surg 1997; 31: 71-75.

99. May JW, Jr., Gallico GGd, Jupiter J, and Savage RC. Free latissimus dorsi muscle flap with skin graft for treatment of traumatic chronic bony wounds. Plast Reconstr Surg 1984; 73: 641-649.

100. McCarthy WJ, 3rd, Matsumura JS, Fine NA, Dumanian GA, and Pearce WH. Combined arterial reconstruction and free tissue transfer for limb salvage. J Vasc Surg 1999; 29: 814-818. 
101. McDaniel MD, Zwolak RM, Schneider JR, Cvonenwett JL, Walsh DB, Reus WF, and Colen LB. Indirect revascularization of the lower extremity by means of microvascular free-muscle flap-a preliminary report J Vasc Surg 1991; 14: 829-830.

102. McKee NH, Clarke HM, Nigra CA, and Manktelow RT. A study of blood flow and pressure in the vessels supplying a free flap. Plast Reconstr Surg 1982; 69: 68-73.

103. McLean D, and Buncke H. Autotransplant of omentum to a large skalp defect with microsurgical revascularization. Plast Reconstr Surg 1972; 49: 268-274.

104. Mizgala CL, Hartrampf CR, Jr., and Bennett GK. Abdominal function after pedicled TRAM flap surgery. Clin Plast Surg 1994; 21: 255-272.

105. Moon HK, and Taylor GI. The vascular anatomy of rectus abdominis musculocutaneous flaps based on the deep superior epigastric system. Plast Reconstr Surg 1988; 82: 815-832.

106. Morrissey WM, Jr., and Hallock GG. The increase in TRAM flap survival after delay does not diminish long term. Ann Plast Surg 2000; 44: 486-490.

107. Muhlbauer W, Herndl E, and Stock W. The forearm flap. Plast Reconstr Surg 1982; 70: 336-344.

108. Musharafieh R, Osmani O, Musharafieh U, Saghieh S, and Atiyeh B. Efficacy of microsurgical free-tissue transfer in chronic osteomyelitis of the leg and foot: review of 22 cases. J Reconstr Microsurg 1999; 15: 239-244.

109. Musser DJ, Berger A, and Hallock GG. Free flap "steal" hastening amputation of a revascularized lower limb. Eur J Plast Surg 1995; 18: 311-313.

110. Nieminen T, Asko-Seljavaara S, Suominen E, Kuokkanen H, and von Smitten K. Free microvascular tram flaps: report of 185 breast reconstructions. Scand J Plast Reconstr Surg Hand Surg 1999; 33: 295-300.

111. Ninkovic MM, Schwabegger AH, and Anderl H. Internal mammary vessels as a recipient site. Clin Plast Surg 1998; 25: 213-221.

112. O'Brien B, MacLeod A, Hayhurst J, and Morrison W. Succesful transfer of a large island flap from the groin to the foot by microvascular anastomosis. Plast Reconstr Surg 1973; 52: 271-278.

113. O'Brien CJ, Lee KK, Stern HS, Traynor SJ, Bron L, Tew PJ, and Haghighi KS. Evaluation of 250 free-flap reconstructions after resection of tumours of the head and neck. Aust N Z J Surg 1998; 68: 698-701.

114. Okadome K, Onohara T, Yamamura S, Mii S, and Sugimachi K. Evaluation of proposed standards for runoff in femoropopliteal arterial reconstructions: correlation between runoff score and flow waveform pattern. A preliminary report. J Cardiovasc Surg 1991; 32: 353-359.

115. Oliva A, Lineaweaver W, and Buncke HJ, Siko P, Jackson RL, Samaha FJ, Alpert BA. Salvage of wounds following failed tissue transplantation. J Reconstr Microsurg 1993; 4: 257-263.

116. Pacifici A, Tinti A, Flamini FO, Cordellini M, Trapassi S, and Dominici C. Colour flow duplex scanning: an accurate, non-invasive technique for preoperative evaluation of the vascular supply of the rectus abdominis myocutaneous flap. Scand J Plast Reconstr Surg Hand Surg 1995; 29: 319-324. 
117. Paulson EK, Sheafor DH, Kliewer MA, Nelson RC, Eisenberg LB, Sebastian MW, and Sketch $\mathrm{MH}, \mathrm{Jr}$. Treatment of iatrogenic femoral arterial pseudoaneurysms: comparison of US-guided thrombin injection with compression repair. Radiology 2000; 215: 403-408.

118. Peterkin GA, Manabe S, LaMorte WW, and Menzoian JO. Evaluation of a proposed standard reporting system for preoperative angiograms in infrainguinal bypass procedures: angiographic correlates of measured runoff resistance. J Vasc Surg 1988; 7: 379-385.

119. Ping P, and Johnson PC. Arteriolar network response to pressure reduction during sympathetic nerve stimulation in cat skeletal muscle. Am J Physiol 1994; 266: H1251-1259.

120. Plass KG. A new ultrasonic flowmeter for intravascular application. IEEE Trans Bio-Med Eng 1964; BME-11: 154-156.

121. Polak JF, Donaldson MC, Dobkin GR, Mannick JA, and O'Leary DH. Early detection of saphenous vein arterial bypass graft stenosis by color-assisted duplex sonography: a prospective study. AJR Am J Roentgenol 1990; 154: 857-861.

122. Polak JF, Karmel MI, Mannick JA, O'Leary DH, Donaldson MC, and Whittemore AD. Determination of the extent of lower-extremity peripheral arterial disease with color-assisted duplex sonography: comparison with angiography. AJR Am J Roentgenol 1990; 155: 1085-1089.

123. Quinones-Baldrich WJ, Kashyap VS, Taw MB, Markowitz BL, Watson JP, Reil TD, and Shaw WW. Combined revascularization and microvascular free tissue transfer for limb salvage: a sixyear experience. Ann Vasc Surg 2000; 14: 99-104.

124. Rand RP, Cramer MM, and Strandness DE, Jr. Color-flow duplex scanning in the preoperative assessment of TRAM flap perforators: a report of 32 consecutive patients. Plast Reconstr Surg 1994; 93: 453-459.

125. Restifo RJ, Ward BA, Scoutt LM, Brown JM, and Taylor KJ. Timing, magnitude, and utility of surgical delay in the TRAM flap: II. Clinical studies. Plast Reconstr Surg 1997; 99: 1217-1223.

126. Ribuffo D, Muratori L, Antoniadou K, Fanini F, Martelli E, Marini M, Messineo D, Trinci M, and Scuderi N. A hemodynamic approach to clinical results in the TRAM flap after selective delay. Plast Reconstr Surg 1997; 99: 1706-1714.

127. Richardson D, Fisher S, Vaughan D, and Brown JS. Radial forearm flap donor site complications and morbidity: a prospective study. Plast Reconstr Surg 1997; 99: 109-115.

128. Rieck B, Mailander P, and Machens HG. Vascular complications after free tissue transfer. Microsurgery $1995 ; 16: 400-403$.

129. Rubertsson S, Arvidsson D, Wiklund L, and Haglund U. Comparison of blood flow measurement in the portal vein and pulmonary artery using transit-time ultrasound flowmetry and thermodilution techniques. Surg Res Comm 1993; 13: 309-316.

130. Rutherford RB, Baker JD, Ernst C, Johnston KW, Porter JM, Ahn S, and Jones DN. Recommended standards for reports dealing with lower extremity ischemia: revised version. J Vasc Surg 1997; 26: 517-538.

131. Rutherford RB, Flanigan DP, Gupta SK, Johnston KW, Karmody A, Whittemore AD, Baker JD, and Ernst CB. Suggested standards for reports dealing with lower extremity ischemia. J Vasc Surg 1986; 4: 80-94. 
132. Salmi A, Ahovuo J, Tukiainen E, Harma M, and Asko-Seljavaara S. Use of ultrasonography to evaluate muscle thickness and blood flow in free flaps. Microsurgery 1995; 16: 601-605.

133. Salmi A, Lamminen A, Tukiainen E, and Asko-Seljavaara S. Magnetic resonance imaging of free muscle flaps. Eur J Plat Surg 1996; 19: 21-25.

134. Salmi A, Tukiainen E, Harma M, and Asko-Seljavaara S. A prospective study of changes in muscle dimensions following free-muscle transfer measured by ultrasound and CT scanning. Plast Reconstr Surg 1996; 97: 1443-1450.

135. Salmi AM, Tierala EK, Tukiainen EJ, and Asko-Seljavaara SL. Blood flow in free muscle flaps measured by color Doppler ultrasonography. Microsurgery 1995; 16: 666-672.

136. Salmi AM, Tukiainen E, and Asko-Seljavaara S. Thermographic mapping of perforators and skin blood flow in the free transverse rectus abdominis musculocutaneous flap. Ann Plast Surg 1995; 35: 159-164.

137. Saltzman D, DeLano FA, and Schmid-Schonbein GW. The microvasculature in skeletal muscle. VI. Adrenergic innervation of arterioles in normotensive and spontaneously hypertensive rats. Microvasc Res 1992; 44: 263-273.

138. Sasmor MT, Reus WF, Straker DJ, and Colen LB. Vascular resistance considerations in free-tissue transfer. J Reconstr Microsurg 1992; 8: 195-200.

139. Sauvage LR, Walker MW, Berger K, Robel SB, Lischko MM, Yates SG, and Logan GA. Current arterial prostheses. Experimental evaluation by implantation in the carotid and circumflex coronary arteries of the dog. Arch Surg 1979; 114: 687-691.

140. Scheufler O, Andresen R, Kirsch A, Banzer D, and Vaubel E. Clinical results of TRAM flap delay by selective embolization of the deep inferior epigastric arteries. Plast Reconstr Surg 2000; 105: 1320-1329.

141. Schusterman MA, Kroll SS, and Weldon ME. Immediate breast reconstruction: why the free TRAM over the conventional TRAM flap? Plast Reconstr Surg 1992; 90: 255-261.

142. Schweiger $\mathrm{H}$, Klein $\mathrm{P}$, and Lang $\mathrm{W}$. Tibial bypass grafting for limb salvage with ringed polytetrafluoroethylene prostheses: results of primary and secondary procedures. J Vasc Surg 1993; 18 : 867-874.

143. Scoutt LM, Zawin ML, and Taylor KJ. Doppler US. Part II. Clinical applications. Radiology 1990; 174: 309-319.

144. Semple JL. Retrograde microvascular augmentation (turbocharging) of a single-pedicle TRAM flap through a deep inferior epigastric arterial and venous loop. Plast Reconstr Surg 1994; 93: 109-117.

145. Serletti JM, Deuber MA, Guidera PM, Herrera HR, Reading G, Hurwitz SR, Jones JA, Ouriel K, and Green RM. Atherosclerosis of the lower extremity and free-tissue reconstruction for limb salvage. Plast Reconstr Surg 1995; 96: 1136-1144.

146. Serletti JM, Deuber MA, Guidera PM, Reading G, Herrera HR, Reale VF, Wray RC, Jr., and Bakamjian VY. Comparison of the operating microscope and loupes for free microvascular tissue transfer. Plast Reconstr Surg 1995; 95: 270-276. 
147. Serletti JM, Hurwitz SR, Jones JA, Herrera HR, Reading GP, Ouriel K, and Green RM. Extension of limb salvage by combined vascular reconstruction and adjunctive free-tissue transfer. J Vasc Surg 1993; 18: 972-978.

148. Serletti JM, Moran SL, Orlando GS, and Fox I. Thoracodorsal vessels as recipient vessels for the free TRAM flap in delayed breast reconstruction. Plast Reconstr Surg 1999; 104: 1649-1655.

149. Siemionow M, Andreasen T, Chick L, and Lister G. Effect of muscle flap denervation on flow hemodynamics: a new model for chronic in vivo studies. Microsurgery 1994; 15: 891-894.

150. Siemionow M, Andreasen T, and Lister G. Microcirculatory response to surgical trauma in compo- $\quad$ site-tissue transfer. J Reconstr Microsurg 1995; 11: 7-13.

151. Singh B, Cordeiro PG, Santamaria E, Shaha AR, Pfister DG, and Shah JP. Factors associated with complications in microvascular reconstruction of head and neck defects. Plast Reconstr Surg 1999; 103: 403-411.

152. Smith AA, Bowen CVA, Rabczak T, and Boyd JB. Donor site deficit of the osteocutaneous radial forearm flap. Ann Plast Surg 1994; 32: 372-376.

153. Sonntag BV, Murphy RX, Jr., Chernofsky MA, and Chowdary RP. Microvascular steal phenomenon in lower extremity reconstruction. Ann Plast Surg 1995; 34: 336-339.

154. Soutar DS, Scheker LR, Tanner NSB, and McGregor IA. The radial forearm flap: A versatile method for intraoral reconstruction. Br J Plast Surg 1983; 36: 1-8.

155. Stack BC, Jr., Futran ND, Shohet MJ, and Scharf JE. Spectral analysis of photoplethysmograms from radial forearm free flaps. Laryngoscope 1998; 108: 1329-1333.

156. Stark B, Nathanson A, Heden P, and Jernbeck J. Results after resection of intraoral cancer and reconstruction with the free radial forearm flap. ORL J Otorhinolaryngol Relat Spec 1998; 60: 212-217.

157. Stevenson TR, Rubin JM, and Herzenberg JE. Vascular patency of fibular free graft: assessment by Doppler color-flow imager: a case report. J Reconstr Microsurg 1988; 4: 409-413.

158. Strandness DE. Duplex Scanning in Vascular Disorders. D.E. Strandness.Hemodynamic of the Normal Arterial and Venous System. New York, Raven Press 1990.

159. Sunderland S. Nerves and Nerve Injuries. 2nd. London, Churchill Livingstone 1978; 298-311.

160. Suominen E, Asko-Seljavaara S, Tuominen H, and Tukiainen E. Free microvascular TRAM flaps for breast reconstruction: the first 50 patients. Eur J Plast Surg 1995; 18: 1-6.

161. Suominen S, and Asko-Seljavaara S. Free flap failures. Microsurgery 1995; 16: 396-399.

162. Suominen S, and Asko-Seljavaara S. Thermography of hands after a radial forearm flap has been raised. Scand J Plast Reconstr Surg Hand Surg 1996; 30: 307-314.

163. Takeishi M, Shaw WW, Ahn CY, and Borud LJ. TRAM flaps in patients with abdominal scars. Plast Reconstr Surg 1997; 99: 713-722.

164. Tamai S. History of microsurgery - from the beginning until the end of the 1970s. Microsurgery 1993; 14: 6-13. 
165. Taylor GI, Corlett RJ, and Boyd JB. The versatile deep inferior epigastric (inferior rectus abdominis) flap. Br J Plast Surg 1984; 37: 330-350.

166. Taylor GI, Corlett RJ, Caddy CM, and Zelt RG. An anatomic review of the delay phenomenon: II. Clinical applications. Plast Reconstr Surg 1992; 89: 408-416.

167. Taylor GI, and Daniel RK. The anatomy of several free flap donor sites. Plast Reconstr Surg 1975; 56: 243-253.

168. Taylor GI, and Townsend P. Composite free flap and tendon transfer: an anatomical study and a clinical technique. Br J Plast Surg 1979; 32: 170-183.

169. Taylor GI, Townsend P, and Corlett R. Superiority of the deep circumflex iliac vessels as the supply for free groin flaps. Plast Reconstr Surg 1979; 64: 595-604.

170. Taylor GI, Watterson PA, and Zelt RG. The vascular anatomy of the anterior abdominal wall: the basis for flap design. Perspect Plast Surg 1991; 5: 1-28.

171. Taylor KJ, and Holland S. Doppler US. Part I. Basic principles, instrumentation, and pitfalls. Radiology 1990; 174: 297-307.

172. Thomson JG, Kim JH, Syed SA, Reid MA, Madsen J, and Restifo RJ. The effect of prolonged clamping and vascular stasis on the patency of arterial and venous microanastomoses. Ann Plast Surg 1998; 40: 436-441.

173. Torre J. Ulnar artery aneurysm with digital ischemia. Vasc Med 1999; 4: 143-145.

174. Towpik E, Mazur S, Witwicki T, Tchorzewska H, and Jackiewicz P. Elevating the island: the simplest method of delaying the TRAM flap. Ann Plast Surg 2000; 45: 240-243.

175. Tukiainen E, Biancari F, and Lepäntalo M. Deep infection of infrapopliteal autogenous vein graftsimmediate use of muscle flaps in leg salvage. J Vasc Surg 1998; 28: 611-616.

176. Tuominen HP, Asko-Seljavaara S, and Svartling NE. Cutaneous blood flow in the free TRAM flap. Br J Plast Surg 1993; 46: 665-669.

177. Tuominen HP, Asko-Seljavaara S, Svartling NE, and Harma MA. Cutaneous blood flow in the TRAM flap. Br J Plast Surg 1992; 45: 261-269.

178. Udesen A, Lontoft E, and Kristensen SR. Monitoring of free TRAM flaps with microdialysis. J Reconstr Microsurg 2000; 16: 101-106.

179. Urbaniak JR, Koman LA, Goldner RD, Armstrong NB, and Nunley JA. The vascularized cutaneous scapular flap. Plast Reconstr Surg 1982; 69: 772-778.

180. van Berge Henegouwen DP, Stelzer G, Dautzenberg T, Helmig L, and Ehresmann U. Pedal and distal lower leg bypasses with a distal arteriovenous fistula. Eur J Vasc Surg 1987; 1: 251-258.

181. van Landuyt K, Vermassen F, Monstrey S, Tonnard P, van de Brande F, and Matton G. Singlestage revascularization and free flap coverage in the treatment of ischemic lower limb lesions. Eur J Plast Surg 1996; 19: 245-243.

182. Vermassen FE, and van Landuyt K. Combined vascular reconstruction and free flap transfer in diabetic arterial disease. Diabetes Metab Res Rev 2000; 16 Suppl 1: S33-36. 
183. Walpoth BH, Aufdermauer P, Falleger B, Baumgartner I, Baumgertner H, Kniemeyer H, Althaus U. Assessment of intraoperative transit time flow and resistance before and after carotid throm bendarterectomy. Proceedings of the 1st Meeting of the European Society of Neurosonology \& 10th International Symposium on Cerebral Hemodynamics, Munchen, Germany, 1996.

184. Walpoth BH, Bosshard A, Genyk I, Kipfer B, Berdat PA, Hess OM, Althaus U, and Carrel TP. Transit-time flow measurement for detection of early graft failure during myocardial revascularization. Ann Thorac Surg 1998; 66: 1097-1100.

185. Walpoth BH, Bosshard A, Kipfer B, Berdat PA, Althaus U, and Carrel T. Failed coronary artery bypass anastomosis detected by intraoperative coronary flow measurement. Eur J Cardiothorac Surg 1998; 14 Suppl 1: S76-81.

186. Walpoth BH, Mohadjer A, Gersbach P, Rogulenko R, Walpoth BN, and Althaus U. Intraoperative internal mammary artery transit-time flow measurements: comparative evaluation of two surgical pedicle preparation techniques. Eur J Cardiothorac Surg 1996; 10: 1064-1068.

187. Wang WZ, Anderson G, and Firrell JC. Arteriole constriction following ischemia in denervated skeletal muscle. J Reconstr Microsurg 1995; 11: 99-106.

188. Watterson PA, Taylor GI, and Crock JG. The venous territories of muscles: anatomical study and clinical implications. Br J Plast Surg 1988; 41: 569-585.

189. Wechselberger G, Rumer A, Schoeller T, Schwabegger A, Ninkovic M, and Anderl H. Free-flap monitoring with tissue-oxygen measurement. J Reconstr Microsurg 1997; 13: 125-130.

190. Weiland AJ, Moore JR, and Daniel RK. The efficacy of free tissue transfer in the treatment of osteomyelitis. J Bone Joint Surg 1984; 66: 181-193.

191. Weinzweig N, and Davies BW. Foot and ankle reconstruction using the radial forearm flap: a review of 25 cases. Plast Reconstr Surg 1998; 102: 1999-2005.

192. Weisel RD, Johnston KW, Baird RJ, Drezner AD, Oates TK, and Lipton IH. Comparison of conduits for leg revascularization. Surgery 1981; 89: 8-15.

193. Whelan JF, Barry MH, and Moir JD. Color flow Doppler ultrasonography: comparison with peripheral arteriography for the investigation of peripheral vascular disease. J Clin Ultrasound 1992; 20:369-374.

194. Wong DH, Watson T, Gordon I, Wesley R, Tremper KK, Zaccari J, and Stemmer P. Comparison of changes in transit time ultrasound, esophageal Doppler, and thermodilution cardiac output after changes in preload, afterload, and contractility in pigs. Anesth Analg 1991; 72: 584-588.

195. Yamamoto Y, Nohira K, Sugihara T, Shintomi Y, and Ohura T. Superiority of the microvascularly augmented flap: analysis of 50 transverse rectus abdominis myocutaneous flaps for breast reconstruction. Plast Reconstr Surg 1996; 97: 79-83.

196. Yuen JC, and Feng Z. Monitoring free flaps using the laser Doppler flowmeter: five-year experience. Plast Reconstr Surg 2000; 105: 55-61.

197. Zierler RE. Duplex and color-flow imaging of the lower extremity arterial circulation. Semin Ultrasound CT MR 1990; 11: 168-179. 